\title{
Mice with Mutations in Trpm1, a Gene within the locus of 15q13.3 Microdeletion Syndrome, Display Pronounced Hyperactivity and Decreased Anxiety- Like Behavior.
}

\section{Tesshu Hori}

Ritsumeikan University: Ritsumeikan Daigaku

Shohei lkuta

Ritsumeikan University: Ritsumeikan Daigaku

\section{Satoko Hattori}

Fujita Health University: Fujita Ika Daigaku

Keizo Takao

Toyama University - Sugitani Campus: Toyama Daigaku - Sugitani Campus

Tsuyoshi Miyakawa

Fujita Health University: Fujita Ika Daigaku

Chieko Koike ( $\sim$ koike@fc.ritsumei.ac.jp)

Ritsumeikan University

\section{Research}

Keywords: 15q13.3 microdeletion syndrome, TRPM1, hyperactivity, ADHD, visual impairment, retinal ON bipolar

Posted Date: December 10th, 2020

DOI: https://doi.org/10.21203/rs.3.rs-122647/v1

License: (c) (i) This work is licensed under a Creative Commons Attribution 4.0 International License. Read Full License

Version of Record: A version of this preprint was published at Molecular Brain on March 30th, 2021. See the published version at https://doi.org/10.1186/s13041-021-00749-y. 


\section{Abstract}

15 q13.3 microdeletion syndrome is a genetic disorder caused by a deletion of a region containing seven genes on chromosome 15, MTMR10, FAN1, TRPM1, MIR211, KLF13, OTUD7A, and CHRNA7, and characterized by a wide spectrum of psychiatric disorders. The contribution of each gene in this syndrome has been studied using mutant mouse models, but the phenotypes of these mice do not account for human phenotypes and the results are still controversial. The behavior of $\mathrm{Trpm} 1^{-/-}$mice with relation to $15 q 13.3$ microdeletion syndrome has not been investigated due to the visual impairment in these mice, which may confound the results of behavior tests that involve vision. We have now applied a comprehensive behavioral test battery to examine the relationship of TRPM1 and 15q13.3 microdeletion syndrome by using Trpm 1 null mutant mice. Our data indicate abnormal behavior of $T r p m 1^{-/-}$mice which may explain some phenotypes of 15q13.3 microdeletion syndrome, including reduction of anxiety behavior, abnormality of social interaction, attenuation in fear memory, and hyperactivity, which is the most prominent phenotype of $T r p m 1$ mutant mice. While the $\mathrm{ON}$ visual transduction pathway is impared in $T r p m 1^{-/-}$mice, we did not detect compensatory high sensitivities for other sensory modalities.

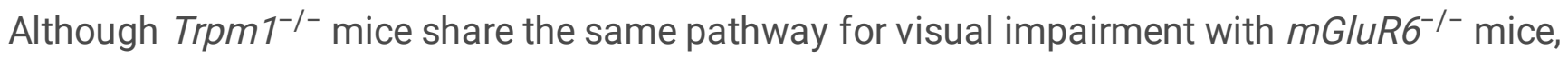
hyperlocomotion activity has not been reported in $m G / u R 6^{-/-}$mice. These data suggest that the phenotype of $\mathrm{Trpm}^{1^{-/-}}$mice extends beyond that expected from visual impairment alone. This is the first evidence to associate TRPM1 with impairment of cognitive function similar to that found in the phenotypes of $15 q 13.3$ microdeletion syndrome.

\section{Introduction}

TRPM1, the first member of the melanoma-related transient receptor potential (TRPM) subfamily to be discovered, is the visual transduction channel downstream of metabotropic glutamate receptor 6 (mGluR6) in retinal ON bipolar cells (BCs) [1,2]. Mutations in TRPM1 are found in humans with an autosomal recessive form of complete congenital stationary night blindness (CSNB) and Trpm1 mutant mice lack a b-wave in the electroretinogram (ERG) and have no light responses in ON BCs [3]. TRPM1 is located in human chromosome $15 q 13.3$, a region that is associated with $15 q 13.3$ microdeletion syndrome, a genetic disorder caused by a deletion encompassing a region of $\sim 1.5$ megabase $(\mathrm{MB})$ from break-point (BP) 4 to BP5, with seven genes; MTMR10; FAN1; TRPM1; MIR211; KLF13; OTUD7A; and CHRNA7 (OMIM \#612001) [4]. Individuals with 15q13.3 microdeletion syndrome have mild to moderate intellectual disorder, mild learning delays, autism spectrum disorder, epilepsy (recurring seizures), attention deficit hyperactivity disorder (ADHD) and mental illnesses including schizophrenia and bipolar disorder [5]. Deletion of CHRNA7 is thought to account for the neuropsychiatric disorder in 15q13.3 microdeletion syndrome, although the phenotype of Chrna7 deficient mice is controversial [6]. Otud7a mutant mice also show many features, including neurological features, in common with those in $15 q 13.3$ microdeletion syndrome, including reduced body weight, developmental delay, abnormal electroencephalogram (EEG) patterns and seizures, reduced ultrasonic vocalizations, decreased grip strength, impaired motor learning/motor coordination, and reduced acoustic startle [7]. 
The role of TRPM1 in behavioral disorders has not been studied, probably because of its strong relationship with vision. TRPM1 and its regulator, mGluR6, both cause CSNB. In mutant retinas, both cause ON but not OFF pathway to fail to respond to light stimuli $[1,8,9]$. We previously reported an unexpected difference between $\mathrm{Trpm}^{-1^{--}}$and $\mathrm{mGluR6^{-/- }}$ mouse retinas. Spontaneous oscillations are observed in $\mathrm{Trpm}^{1^{-/-}}$retinas, but not in $\mathrm{mGluR6^{-/- }}$ retinas by recording spiking in retinal ganglion cells (RGCs) using a multielectrode array (MEA) [10]. We also previously reported that rod ON BC terminals were significantly smaller in $T r p m 1^{-/-}$retinas than those of $m G / u R 6^{-/-}[10]$. These data suggest that a deficiency of TRPM1, but not of mGluR6, in rod ON BCs may effect synaptic terminal maturation and could underlie the observed differences in oscillatory response. Spurred on by the observation of Trpm1deletion specific RGC oscillations and a gene location in the targeted region of 15q13.3 microdeletion syndrome, we searched for central and behavior changes that might attribute to a persistent, rhythmic visual outflow.

In this study, we thoroughly examined $T r p m 1^{-/-}$mice with a battery of behavioral tests [11]. We also examined structural and functional change in $\mathrm{Trpm}^{-/-}$mouse brain, which may explain the abnormal behaviors of this mutant as a model of $15 q 13.3$ microdeletion syndrome.

\section{Methods}

\section{Animals and Experimental Design}

$\operatorname{Trpm} 1^{-/-}$mice were generated as described previously [1]. In this study, we analyzed $\operatorname{Trpm} 1^{-/-}$mice with their wild type (WT) littermates on the 129 Sv/Ev Taconic background. All behavioral tests were performed with male that were 11-12 weeks old at the starting of the testing (Trpm 1 ${ }^{-/-}$mice, $n=24$; WT littermates, $n=24$ ). Mice were housed as 2 pairs of $\mathrm{Trpm}^{-1-}$ and WT mice in a cage with a 12- hour light/dark cycle (light on 7:00 a.m. and off 7:00 p.m.). All mice had access to food and water ad libitum. Behavioral testing was performed between 8:30 A.M. and 6:30 P.M. unless otherwise noted. Our behavioral test battery consists of the tests listed in Table 1. After the tests, all the testing apparatus were cleaned with diluted hypochlorous solution or $70 \%$ ethanol to prevent a bias due to olfactory cues.

Brain weight measurement and monoamine quantification in brain tissues were performed with $129 \mathrm{~Sv} /$ Ev male at 4 months (Trpm 1/- mice, $n=24$; WT littermates, $n=24)$ or 1 months $\left(\operatorname{Trpm}^{-/-}\right.$mice, $n=4$; WT littermates, $n=5$ ). Gene expression analysis was performed with $129 \mathrm{~Sv} / \mathrm{Ev}$ male at 1 months (WT, $n=5$ ). Mice used for monoamine quantification were housed as 2 pairs of $T r p m 1^{-1-}$ mice and WT mice in a cage with a 12- hour light/dark cycle (light on 8:00 a.m. and off 8:00 p.m.), and tissue dissection was performed at the same time point (1:00 p.m.). All mice had access to food and water ad libitum. The experimental procedures and housing conditions for animals were approved by Institutional Animal Care and Use Committee of National Institute for Physiological Sciences, Fujita Health University and Ritsumeikan University.

\section{General health and neurological screen}


A general health and neurological screen examined the body weight, rectal temperature, whisker, coat, simple reflexes such as righting, whisker touch, eye blink, ear twitch reflexes and reaching behavior using $11 \sim 12$ weeks old, as described previously [12]. Grip strength test and wire hang test were conducted to measure muscle strength. Grip strength was measured by using a grip strength meter (O'Hara \& Co., Japan). In the wire hang test, the mouse was placed on a wire cage lid that was then inverted, so that the subject gripped the wire. Latency to fall onto the bedding was recorded, with a 60 sec cutoff time.

\section{Light/dark transition test}

Light/dark transition test was performed as described previously [13-15]. The apparatus used for light/dark transition test consisted of a cage $(21 \times 41.5 \times 25 \mathrm{~cm})$ divided into two sections of equal size by a partition with a door (O'Hara \& Co., Japan). One section was brightly illuminated (390 \pm 20 lux), whereas the other section was dark ( $<2$ lux). Mice were placed into the dark side of the apparatus, and allowed to move freely between the two sections for $10 \mathrm{~min}$, while the door remained open. In the same way, mice (34-35 weeks old) were placed into the light side of the apparatus allowed to move freely between the two sections for $10 \mathrm{~min}$. The total number of transitions, time spent in each section, initial latency to the light section, and distance traveled were recorded automatically using Image LD software.

\section{Open field test}

Open field test was performed as described previously $[14,15]$. Mice was allowed to move freely in an open field apparatus ( $40 \times 40 \times 30 \mathrm{~cm}$; Accuscan Instruments, U.S.A.), which was illuminated at $10.0 \mathrm{~lx}$ for $120 \mathrm{~min}$. Each subject was placed in the corner of the apparatus. The total distance, vertical activity (rearing measured by counting the number of photobeam interruptions), time spent in the center area, and stereotypic behaviors were recorded.

\section{Elevated plus maze test}

Elevated plus maze test was performed as described previously $[14,16]$. The apparatus (O'Hara \& Co., Japan) consisted of two open arms $(25 \times 5 \mathrm{~cm})$ and two enclosed arms of the same size, with central square $(5 \times 5 \mathrm{~cm})$. The closed arms have $16 \mathrm{~cm}$ high transparent walls. To minimize the likelihood of animals falling from the apparatus, 3-mm-high Plexiglas ledges were provided for the open arms. The arms and were made of white plastic plates and were elevated to a height of $50 \mathrm{~cm}$ above the floor. Arms of the same type were arranged at opposite sides to each other. Mice was placed in the central square of the maze, facing one of the closed arms and behavior was recorded during a 10-min test period. The percentage of open arm entries, the percentage of time spent on the open arms, the total number of arm entries, and total distance traveled were measured automatically using Image EP software.

\section{Hot plate test}

Hot plate test was performed as described previously [16]. Mice were placed on a $55.0^{\circ} \mathrm{C}$ hot plate (Columbus Instruments, U.S.A.), and latency to the first hind paw response was recorded. The hind paw response was either a foot shake or a paw lick.

\section{Social interaction test}


Social interaction test was performed as described previously [16]. A pair of mice (12-13 weeks old) was placed simultaneously at opposing corners in the open field apparatus $(40 \times 40 \times 30 \mathrm{~cm}$; O'Hara \& Co., Japan), whose illumination level was $10.0 \mathrm{~lx}$ at the center of the floor, and allowed to explore freely for $10 \mathrm{~min}$. The pair of mice had been housed in different cages. The number of active contacts, the number of contacts, mean duration per contact, total duration of contact, and total distance traveled were measured. Analysis was performed automatically using Image SI software.

\section{Rota-rod test}

Motor coordination and balance were tested with the rota-rod test old as described previously [16]. The rota-rod test using an accelerating rota-rod (UGO Basile, Italy) was performed by placing a mouse on a rotating drum ( $3 \mathrm{~cm}$ diameter) and measuring the time each animal was able to maintain its balance on the rod. The speed of the rota-rod accelerated from 4 to $40 \mathrm{rpm}$ over a 5 -min period.

\section{Social approach and novelty preference test}

Social approach and preference for social novelty were tested with the The three-chamber social approach test as described previously $[14,16]$. The apparatus comprised a rectangular, three-chambered box and a lid with a video camera (O'Hara\& Co., Japan). Each chamber was $20 \mathrm{~cm} \times 40 \mathrm{~cm} \times 22 \mathrm{~cm}$ and the dividing walls had small openings $(5 \mathrm{~cm} \times 3 \mathrm{~cm})$ to allow exploration into each chamber. The day before testing, the mice were individually placed in the middle chamber and allowed to freely explore the entire apparatus for $10 \mathrm{~min}$. During the test session, the amount of time spent in each chamber and time spent around each cage were recorded and analyzed automatically using Image CSI.

\section{Acoustic Startle response/prepulse inhibition tests}

Acoustic Startle response/prepulse inhibition tests were performed as described previously [16] (O'Hara \& Co., Japan). A test session began by placing a mouse in a Plexiglas cylinder where it was left undisturbed for $10 \mathrm{~min}$. The duration of white noise that was used as the startle stimulus was $40 \mathrm{msec}$ for all trial types. A test session consisted of six trial types (i.e., two types for startle stimulus-only trials and four types for prepulse inhibition trials). The intensity of startle stimulus was 110 or $120 \mathrm{~dB}$. The prepulse was presented $10.0 \mathrm{msec}$ before the startle stimulus, and its intensity was 74 or $78 \mathrm{~dB}$. Four combinations of prepulse and startle stimuli were used $(74-110,78-110,74-120$, and 78-120). Six blocks of the six trial types were presented in pseudorandom order such that each trial type was presented once within a block. The average intertrial interval was $15 \mathrm{sec}$ (range, 10-20 sec).

\section{Porsolt Forced Swimming test}

Depression-related behavior was assessed, using the forced swimming test as described previously [12]. The apparatus consisted of Plexiglas cylinders (22 cm height $x 12 \mathrm{~cm}$ diameter). The cylinders were filled with water (room temperature, $23 \pm 2{ }^{\circ} \mathrm{C}$ ), up to a height of $7.5 \mathrm{~cm}$. Mice were placed into the cylinders, and their behavior was recorded over a 10-min test period. Immobility and distance traveled were measured analyzed automatically using Image PS software.

\section{Gait analysis}


The gait during walk/trot locomotion was assessed using DigiGait Imaging System (Mouse Specifics, U.S.A.) as described previously [17]. Digital video images of the underside of mice were collected at 150 frames per second. We placed the mice on a treadmill belt that moves at a speed of $24.7 \mathrm{~cm} / \mathrm{s}$. The percent of the time of stride or stance duration, stride length, stance width, step angle and paw angle were calculated.

\section{Barnes maze}

The Barnes maze test was performed as described previously [12]. The circular open field (O'Hara \& Co., Japan) was elevated $97 \mathrm{~cm}$ from the floor. Training session were conducted one to three per day. After 24 hours after 15th training session, a probe test was conducted without the escape box, to confirm that this spatial task was acquired based on navigation by distal environmental room cues. One month after last (16th) training session, probe trial tests were conducted again to evaluate memory retention. After five additional training sessions conducted after the memory retention test, the escape box was moved to a new position opposite to the original (reversal learning). Mice were then trained with 8 sessions to locate the new position of the escape hole using the same procedure as described above. Latency to reach the target hole, distance to reach the target hole, number of errors and time spent around each hole were recorded automatically using Image BM software.

\section{T-maze Spontaneous Alteration}

T-maze spontaneous alteration test was performed as described previously [15] using the automatic modified T-maze apparatus (O'Hara \& Co., Japan). Mice were subjected to a the spontaneous alteration protocol for 5 sessions. One session consists of 10 choices with a 50-min cutoff time. Mice were first placed in the start compartment of the T-Maze. Mice chose entering either the left or the right arm and could return to the start compartment. The mice was then given a 3-sec delay followed by a free choice between both $\mathrm{T}$ arms. A correct choice was made if the mouse entered the arm which was not visited in the previous choice. The percentage of correct response, latency (sec) to complete a session, distance traveled during the session. Data acquisition was performed automatically using Image TM software.

\section{Tail suspension test}

Depression-related behavior was assessed by the tail suspension test as described previously [17]. Mice were suspended $30 \mathrm{~cm}$ above the floor in a visually isolated area by adhesive tape placed, $1 \mathrm{~cm}$ from the base of the tail, and their behavior was recorded over a 10-min test period. Data acquisition and analysis were performed automatically using Image TS software.

\section{Contextual and cued fear conditioning}

The ability of mice to learn and remember an association between environmental cues and aversive experiences was assessed by fear conditioning test as described previously $[15,16]$. Each mouse was placed in a test chamber $(26 \times 34 \times 33 \mathrm{~cm}$, O'Hara \& Co., Japan $)$ and allowed to explore freely for $2 \mathrm{~min}$. A $55 \mathrm{~dB}$ white noise, which served as the conditioned stimulus (CS), was presented for $30 \mathrm{sec}$. Next, a mild (2 sec, $0.3 \mathrm{~mA}$ ) foot shock, which served as the unconditioned stimulus (US), was presented immediately 
after the CS. Two more CS-US pairings were presented with a 2-min interstimulus interval. Context testing was conducted 1 day after conditioning in the same chamber for $30.0 \mathrm{sec}$ without CS and US presentations.

Cued testing with altered context was conducted after conditioning using a triangular box $(33 \times 33 \times$ $33 \mathrm{~cm}$ ) made of white opaque Plexiglas, which was located in a different room. Mice are allowed to explore the chamber for $360 \mathrm{sec}$. In the first $3 \mathrm{~min}$, neither a CS nor US is presented, then a CS (a $55 \mathrm{~dB}$ white noise) is presented for the last 3 min. Freezing and distance traveled were recorded. Data acquisition, control of stimuli (i.e. tones and shocks), and data analysis were performed automatically using Image FZ software.

\section{Twenty-four hour home cage monitoring test}

The 24-hour home cage test was performed as described previously [15]. The system for monitoring social interaction comprised a home cage $(19 \times 29 \times 13 \mathrm{~cm})$ and a filtered cage top with an infrared video camera (O'Hara \& Co., Japan). Two mice with the same genotype that had been housed separately were placed together in a home cage. To evaluate their locomotor activity and social interaction, their behavior was monitored with a video camera for a week. Distance traveled was measured auto- matically using ImageHA software. The occurrence of social interaction was detected by counting the number of particles consisting of the mice as follows: 2 particles indicated that the mice were not in contact whereas 1 particle indicated that 2 mice were in contact. Locomotor activity of the mice was also measured.

\section{Methylphenidate administration in the open field}

After the behavioral test battery, the behavioral response to methylphenidate (MPH) was assessed in the open filed. A quarter of the area of the open field apparatus $(20 \times 20 \times 30 \mathrm{~cm})$ was used by installing a divider. Other conditions were the same as for the open filed test. The mice of each genotype were randomly divided into two groups for treatment with MPH and saline. The experiment was repeated twice with varying drug doses. Locomotor activity was recorded continuously during the 60-min habituation period and for $120 \mathrm{~min}$ after injection of saline or MPH (3 mg/kg or $10 \mathrm{mg} / \mathrm{kg})$.

\section{Monoamine quantification in brain tissues}

Monoamine transmitter quantification was performed as described previously [18]. Tissue concentrations of biogenic monoamines were analyzed after dissection in various brain regions; prefrontal cortex, hippocampus, striatum, cerebral cortex, olfactory bulb, cerebellum, midbrain, pons and medulla, thalamus, hypothalamus. The weight of the brain tissue was measured, and homogenized in $0.2 \mathrm{M}$ icecold perchloric acid (including $10.0 \mu \mathrm{M} E D T A \otimes 2 \mathrm{Na}$ ) and the homogenates were cooled on ice for 30 min to deproteinize. The homogenates were centrifuged at $20,000 \mathrm{G}$ for $15 \mathrm{~min}$ at $0{ }^{\circ} \mathrm{C}$. Then, the $\mathrm{pH}$ of the supernatant was adjusted to approximately 3.0 by adding $1 \mathrm{M}$ sodium acetate. The samples were filtered through a $0.45 \mathrm{~mm}$ filter (Millipore, Billerica, USA). Next, $10 \mu \mathrm{L}$ of filtrate was loaded into a high performance liquid chromatography (HPLC) system (Eicom, Japan). The HPLC system had a $\varnothing 3.0 \mathrm{~mm} x$ $150 \mathrm{~mm}$ octadecyl silane column (SC-5ODS, Eicom), and an electrochemical detector (ECD) (HTEC-50.0; 
Eicom, Japan) set to an applied potential of $+750 \mathrm{mV}$ versus an $\mathrm{Ag} / \mathrm{AgCl}$ reference analytical electrode. The change in electric current (nA) was recorded using a computer interface at $25^{\circ} \mathrm{C}$. The mobile phase was composed of $0.1 \mathrm{M}$ aceto-citric acid buffer ( $\mathrm{pH} 3.5)$, methanol, sodium-1-octane sulfonate $(0.46 \mathrm{M})$, and EDTA囚2Na (0.015 mM) [830: 170: 1.9: 1]. The flow rate was $0.5 \mathrm{~mL} / \mathrm{min}$.

\section{Gene expression analysis in the brain}

Total RNA was isolated from each brain part using Biomasher $\$ (nippi, Japan) and ISOGEN $\triangle$ (NIPPON GENE, Japan). For complementaly DNA (cDNA) synthesis, $1 \mu \mathrm{g}$ of total RNA was reverse transcribed (RT)

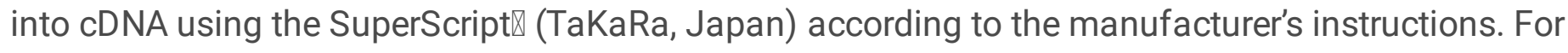
quantative polymerase chain reaction (qPCR) was conducted on a Thermal Cycler Dice ${ }^{\circledR}$ Real Time System $\otimes\left(\right.$ (TaKaRa, Japan) using TB Green ${ }^{\circledR}$ Premix Ex Taq ${ }^{\text {TM }} \otimes$ (Tli RNaseH Plus) (TaKaRa, Japan) according to the manufacturer's instructions. Primers for mouse Trpm1: forward, 5'-

GAGATGCAGCCCAAACTGAAGC-3'; reverse, 5'-TGACGACACCAGTGCTCACA-3'. Primers for mouse b-actin: forward, 5'- CTCTGGCTCCTAGCACCATGAAGA - 3'; reverse, 5'- GTAAAACGCAGCTCAGTAACAGTCCG - 3'.

\section{Corticosterone measurement}

Blood was collected from mice at 4 months old by Cardiac puncture immediately after cervical dislocation. A serum was separated by centrifuging at 2,000 $\mathrm{g}$ for $20 \mathrm{~min}$, and stored at $-80{ }^{\circ} \mathrm{C}$ until use. Corticosterone measurements were performed on serum by enzyme-linked immuno sorbent assay (ELISA) using a Corticosterone immunoassay (R\&D Systems, U.S.A.) according to the manufacturer's instructions.

\section{Image analysis}

Behavioral data were obtained automatically by customized applications based on a public domain Image J program (Image LD, Image EP, Image SI, Image CSI, Image PS, Image BM, Image TM, Image TS, Image FZ, Image HA). The ImageJ plugins, and the precompiled plugins for light/dark transition test (Image LD), elevated plus maze (Image EP), open field test (Image OF), fear conditioning test (Image FZ), and T-maze (Image TM) are freely available on the website of "Mouse Phenotype Database" (http://www.mouse-phenotype.org/software.html) .

\section{Data analysis}

All statistical analyses were performed using Graph Pad Prism7. Statistical methods are indicated in the figure legends. Data are presented as mean \pm SEM. Unpaired 2-tailed Student's $t$ test or Welch's $t$ test were used for 2-group comparisons. Two-way analysis of variance (ANOVA) or repeated-measures two-way ANOVA following Tukey's test and one-way ANOVA following Dunnett's test was used for multiple comparison. Unless otherwise noted, the $p$ values are for the genotype effect.

\section{Data repository}

The raw data of the behavioral tests and the information about each mouse are accessible on the public database "Mouse Phenotype Database" (http://www.mouse-phenotype.org/). 


\section{Results}

$\operatorname{Trpm} 1^{-/-}$mice show significantly high daily locomotor activity.

We performed a battery of more than 20 behavioral tests (Table 1). There was almost no significant difference for general physical characteristics, such as body weight, body temperature, grip strength, and motor coordination between $\mathrm{Trpm}^{-/-}$and wild type mice (Fig. S1A-K). Trpm $1^{-/-}$did not show depression-like behaviors in Porsolt forced swim test and tail suspension test (Fig. S1L-N). Intriguingly,

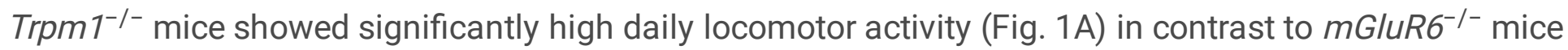
[19]. It has been reported that the absence of vision in human and animals enhances auditory, haptic, and pain sensitivities [20-29], and causes structural changes in the visually deprived cortex and in other areas $[23,30,31]$. We examined sensory responses in $\mathrm{Trpm}^{-/-}$mice, but we did not find any significance difference between Trpm1/-- mice and wild type for the hot plate test, the acoustic startle response, and prepulse inhibition (Fig. 1B-D). Although $T r p m 1^{-/-}$mice lack a functional ON visual pathway and thus have limited light responses, $\operatorname{Trpm} 1^{-/-}$mice showed hyper- locomotor activity but did not show sensory hypersensitivities that was reported in other visually impaired animals.

Hyperactivity and reduction of anxiety-like behavior in $\mathrm{Trpm}^{-1 /-}$ mice

To assess anxiety-like behavior, we performed the light/dark transition test, the open-field test, and the elevated plus maze test (Fig. 2). In the light/dark transition test, distance traveled in the light and dark chamber were significantly increased in $\mathrm{Trpm}^{-/-}$mice suggesting a reduction in anxiety-like behavior (Fig. 2A). However, the defect in the $\mathrm{ON}$ visual pathway may have affected the longer stay time in light and increased transition time and shorter latency to light for tests started at dark (Fig. 2B-D). In the open field test, which measures voluntary locomotor activity in a novel environment, $\operatorname{Trpm}^{1^{-/-}}$mice exhibited a significant increase in total distance, vertical activity, center time and stereotypic behavior relative to WT mice (Fig. 2E-H), suggesting strong hyperactivity, which also explains longer distance traveled in the light/dark transition test. To implicate the hyperactivity in $\mathrm{Trpm1^{-/- }}$ mice with ADHD, we performed the open field test after administration of MPH, which is often used as a first choice for treatment of ADHD in human (Fig. 2I) [32]. 120 min after administration of MPH, both WT and Trpm1 ${ }^{-/-}$mice showed prominent hyperactivity, especially in mice which were injected at $10 \mathrm{mg} / \mathrm{kg}$. As a result, MPH administration did not support the idea that the ADHD behavior displayed in $T r p m 1^{-/-}$mice can be reduced by MPH administration [33].

Additionally, in the elevated plus maze test, $\mathrm{Trpm}^{-1-}$ mice exhibited significantly increased numbers of entries and longer traveled distance, which are also explained by hyperactivity (Fig. 2J, M). Although visually impaired, $\mathrm{Trpm}^{-/-}$mice did not show differences for entries to open arms, but stayed longer time in open arms suggesting a reduction of anxiety-like behavior (Fig. 2K, L). 
To examine what causes a reduction in anxiety-like behavior in $\mathrm{Trpm} 1^{-/-}$mice, we examined serum corticosterone levels in $\mathrm{Trpm}^{-/-}$mice by ELISA [34,35]. The idea is that an authentic reduction in anxiety should be correlated with an decrease in serum corticosterone levels, while a reduction in anxiety-like behavior in the absence of a decrease may have some other cause. The serum levels of corticosterone were not significantly different between $\mathrm{Trpm}^{-/-}$mice and WT mice (Fig. S10). This observations suggests that the hyperactivity of $T r p m 1^{-/-}$mice simulates a reduction of anxiety in our tests.

Abnormal social interaction in $\operatorname{Trpm}^{-1 /-}$ mice

Four kinds of social interaction tests (novel environment, sociability, novelty preference, and home cage test) were performed to evaluate social behaviors in the $\mathrm{Trpm}^{-/-}$mice (Fig. 3). The novel environment test revealed significant differences between $\mathrm{Trpm} 1^{-/-}$and WT mice, including a shorter duration per contact, increased contact number, and total traveled distances, which may be explained by the hyperactivity in $\mathrm{Trpm}^{-/-}$mice (Fig. 3A, D, E). Although total duration of contact was shortened, but not significantly, active contacts were longer in Trpm $1^{-/-}$mice (Fig. 3B, C). Both Crawley's sociability and social novelty preference test and the test in the home cage did not reveal significant differences between WT and mutant mice (Fig. 3F-M, S1P). These results suggest that social interactions were attenuated in $\mathrm{Trpm}^{1^{-/}}$mice, which may be partially explained by hyperlocomotion behavior.

Attenuation of fear and spatial memories in $\mathrm{Trpm}^{-/-}$mice

The contextual and cued fear conditioning test is used to assess fear memory (Fig. 4). In the conditioning phase, $\mathrm{Trpm}^{1^{-/-}}$mice showed a lower level of freezing and traveled longer distances during sessions (Fig. 4A, B). The mutant mice traveled longer immediately after foot shock, an index of pain sensitivity (Fig. 4C). 24 hours after conditioning, Trpm $1^{-/-}$mice showed decreased freezing and increased distance traveled. Similar significant differences were observed in tests 28 days after conditioning (Fig. 4D, E). These data suggest that attenuation of fear memory in $\mathrm{Trpm}^{-/-}$mice could be related to hyperactivity.

We performed the Barnes maze test to determine whether the deficit in fear memory of $T r p m 1^{-/-}$ contributes to hyper-locomotion or results from a deficit of memory. In both training sessions and reversal task tests, the distance to the escape box (Fig. 4F) and the number of errors to reach the escape box were significantly higher in $\mathrm{Trpm} 1^{-/-}$mice (Fig. 4G), but latency to first reach the escape box was equivalent or shorter in $\mathrm{Trpm}^{-/-}$mice than in WT mice (Fig. 4H), which may be related to hyper- locomotion activity. The probe tests were performed 24 hours and 1 month after the final training sessions. In these tests, $\mathrm{Trpm}^{1 /-}$ and WT mice exhibited a significant effect of hole location target against the rest holes: 24 hour, WT $p<0.0001, T_{r p m} 1^{-/-} p<0.0001 ; 1$ month, WT $p<0.0001, \operatorname{Trpm}^{-/-} p<0.0001$; one-way ANOVA followed by Dunnett's multiple comparison test), indicating that both genotypes were able to distinguish the location of the target. Time spent around the correct hole did not differ significantly between both genotypes at 24 hours after training, but was significantly shorter in $\mathrm{Trpm}^{-1-}$ mice 1 month later (Fig. 4I, J). These results suggest that $\mathrm{Trpm}^{-1-}$ mice have a deficit in long-term memory. In the reversal probe 
test, although both genotypes distinguished the location of the target (WT $p<0.0001, \operatorname{Trpm} 1^{-1-} p<$ 0.0001; one-way ANOVA followed by Dunnett's multiple comparison test), there was no significant difference in time spent around the correct hole between both genotypes (Fig. 4K). This result indicates that there was no deficit in behavioral flexibility in $\mathrm{Trpm}^{-1-}$ mice. We also performed a T-maze test to examine the working memory of $\mathrm{Trpm}^{-/-}$mice. Although the shorter latency and longer distance traveled in $\mathrm{Trpm}^{-/-}$mice were both significantly different, the correct responses at each trial were not (Fig. 4L-N). Taken together, Trpm $1^{-/-}$mice showed attenuation for fear and long term memories, but no obvious deviation for flexibility and working memory.

Abnormal Structural and biochemical changes in the brains of $\operatorname{Trpm} 1^{-/-}$mice

We have shown differences in the behavioral phenotype in $\operatorname{Trpm}^{-/-}$mice relative to WT. However, Trpm1 functions predominantly as a component of the retinal ON bipolar transduction cascade and its expression is quite minor in the brain. To determine whether there are central structural changes, we compared brain regions between $\mathrm{Trpm}^{1^{-/-}}$and WT mice. The cerebral cortex, olfactory bulb, and pons and medulla of $\mathrm{Trpm}^{-/-}$mice were significantly heavier than in WT mice at 1 month old (Fig. 5A). In addition, the cerebral cortex, hippocampus, midbrain and cerebellum of $\mathrm{Trpm}^{-/-}$mice were significantly heavier than those of WT mice at 4 months old (Fig. 5B).

We detected a subtle expression of Trpm1 mRNA throughout the WT mouse brain with the exception of the cerebellum (Fig. $5 \mathrm{C}$ ). We also quantified levels of biogenic monoamines ex vivo, including dopamine (DA), noradrenaline (NAd), serotonin (5-HT), and their major metabolites using HPLC-ECD in several adult brain regions. Levels of DA, NA, and NM were significantly decreased in the cerebellum (Fig. 5D-F). There was no significant change in the levels of the other monoamines and their metabolites in any other brain region (Fig. S2). The decreased levels of monoamines in the cerebellum of $\mathrm{Trpm}^{-1 /}$ mice could influence hyper-locomotory activity, locomotion is regulated by the cerebellum. The lack of overlap between the Trpm1 expression pattern and the change of monoamine distribution in the brain is consistent with the idea that Trpm1 expresses in monoaminergic neurons that project to the cerebellum.

\section{Discussion}

15q13.3 microdeletion syndrome shows a spectrum of neurobehavioral phenotypes in human patients. So far, several investigations have suggested that mutants that abolish the functions of OTUD7A and CHRNA7 can partially explain the phenotypes of 15q13.3 microdeletion syndrome. However, we still lack a full accounting for the microdeletion phenotypes, especially those related to hyperactivity. In this paper, we examined the behavior of Trpm 1 deficient mice with a comprehensive behavioral test battery. Our data show abnormal behaviors in Trpm 1 deficient mice including a reduction of anxiety behavior, an abnormality of social interaction, the attenuation of fear and spatial memories, and hyper-locomotion activity, which is the most prominent phenotype of Trpm1 mutant mice and may also underlie or contribute to other phenotypes of $\operatorname{Trpm}^{-/-}$mice (Fig. 1-3). Hyperactivity is one of the features of ADHD, 
and a patient with 15q13.3 deletion, who had a relative lack of expression of genes including TRPM1, showed ADHD behavior [36-43]. We examined the effect of MPH which is often used for treatment of ADHD, however, MPH significantly increase the locomotion activity of $\operatorname{Trpm}^{-1-}$ mice (Fig. 2I). Intriguingly, $\mathrm{MPH}$-like compounds were ineffective in approximately $35 \%$ of patients with $\operatorname{ADHD}[44,45]$. There are several mouse models of hyperactivity which were also insensitive to MPH. In Ndrg2 deficient mice, their ADHD-like hyperactivity was not rescued by MPH [46]. Shank2 and Fmr1 mutant mice, both are the model of autism, display hyperactivity, but the injection of MPH increased their locomotion activity [47, 48]. Relevant to the effect of MPH in Shank2 and Fmr1 deficient mice, hyperactivity in Trpm1 deficient mice may not be related to ADHD, but instead autism which is also one of the phenotypes in $15 q 13.3$ microdeletion syndrome (Table S1) [5, 49].

Trpm $1^{-/-}$mice showed prominent locomotion activities (Fig. 1A, 2E) that are not observed in $m G / u R 6^{-/-}$ mice [19]. Both mice lack of a functional ON visual transduction pathway and lack a b-wave in the ERG [3, 50] as well as having no ON response [1, 8, 9]. Additional evidence for visual impairment in Trpm $1^{-/-}$mice comes from measurements of the spatial frequency and contrast sensitivity thresholds of the optokinetic response (OKR) was repotrted. Thresholds were reduced by approximately $10 \%$ and $30 \%$, respectively, compared to WT [51]. While both mGluR6 and Trpm 1 deficient mice lack ON BCs responses, spontaneous oscillatory firing in RGCs, the output cells of the retina, was only detected in $\mathrm{Trpm}^{1^{-/-}}$mice [10]. An attractive idea is that these retinal oscillations might be communicated along the optic nerve to higher visual centers and result in hyperlocomotion in $\mathrm{Trpm}^{1^{-/}}$mice.

Visual impairment can cause behavioral abnormalities in human and mice related to hypersensitivity to sensory stimuli. Moreover, the visual cortex eceives feedback projections from auditory and somatosensory cortex as well as from motor and multisensory cortices [22, 52-56]. However, Trpm1 $1^{-/-}$ mice did not show hypersensitivity to sensory stimuli, which is observed in visually impaired animals as well as in human patients [20-29], at least for thermal perception and auditory responses (Fig. 1B-D). Thus is it unlikely that the behavioral changes in $\mathrm{Trpm}^{-1-}$ mice are secondary to changes in non-visual sensory perception.

There is another possible explanation for the behavioral phenotypes in $\mathrm{Trpm}^{-1 /}$ mice. The expression of mGluR6 is known to be restricted to retinal ON BCs, whereas TRPM1 is expressed in the retina and skin in humans [57-59], and a short form of TRPM1, which does not have channel function, is expressed in embryonic retinal pigment epithelial and skin in mouse $[1,2]$. Thus, there is a precedent for the expression of TRPM1 outside of the retina, including alternate splice forms. We analyzed the expression of Trpm 1 in the brain and detected a faint expression by qPCR thoughout most of the brain with the exception of the cerebellum (Fig. 5C). Thus, Trpm1 may be expressed in some parts of brain and the presence or lack of Trpm1 in a particular region may effect behavior. A link between TRPM1 and brain function was previously suggested by the demonstration that capsaicin-induced activation of TRPM1 channels contributed to the induction of long-term depression (LTD) in the lateral amygdala, which was specifically mediated by group I mGluRs and via interactions with another member of the TRP family, TRPC5 [60]. 
Deficiency of Trpm1 expression in the brain including the amygdala may lead to a neurochemical attenuation in brain function that may cause behavioral phenotypes in $\operatorname{Trpm} 1$ deficient mice similar to those demonstrated here.

In summary, our results are consistent with the idea that spontaneous oscillatory firing in the retina may be transmitted to the higher visual system through the optical nerve and more central projections during development and after, and as a result may modify the function and structure of the brain leading to the observed behavior changes. An alternate but not mutually exclusive view is that the lack of expression of Trpm1 in the brain may change the distribution of biogenic monoamines and behaviors in $\mathrm{Trpm} 1^{-/-}$mice. Irrespective of the mechanism, this is the first report to implicate TRPM1 loss in 15q13.3 microdeletion syndrome. Further experiments will be required to determine if retinal dysfunction causes the alteration in the brain, or whether there is a specific contribution of $\operatorname{Trpm} 1$ in certain brain regions.

\section{Abbreviations}

\section{TRPM1}

melanoma-related transient receptor potential, mGluR6 metabotropic glutamate receptor 6

$\mathrm{BC}$

bipolar cell

CSNB congenital stationary night blindness

ERG electroretinogram

MB

megabase

$\mathrm{BP}$

break-point

MTMR10

myotubularin related protein 10

FAN1

FANCD2 And FANCl associated nuclease 1

KLF13

Kruppel-like factor 13

OTUD7A

OTU deubiquitinase 7A

CHRNA7

cholinergic Receptor Nicotinic Alpha 7 Subunit

ADHD 
attention-deficit hyperactivity disorder

EEG

electroencephalogram

RGC

retinal ganglion cell

MEA

multielectrode array

WT

wild-type

CS

conditioned stimulus

US

unconditioned stimulus

$\mathrm{MPH}$

methylphenidate

HPLC

high performance liquid chromatography

ECD

electrochemical detector

cDNA

complementary DNA

RT

reverse transcribed

qPCR

quantative polymerase chain reaction

ELISA

enzyme-linked immuno sorbent assay

ANOVA

analysis of variance

DA

dopamine

NA

noradrenaline

$5-\mathrm{HT}$

5-hydroxytryptamine (serotonin)

OKR

optokinetic response

LTD

long-term depression

DOPAC 
3,4-dihydroxyphenylacetic acid

3-MT

3-methoxytyramine

HVA

omovanillic acid

$\mathrm{Ad}$

adrenaline

NM

normetanephrine

MHPG

3-methoxy-4-hydroxyphenylglycol

5 -HIAA

5-hydroxyindoleacetic acid

\section{Declarations}

Ethics approval and consent to participate

All experimental procedures and housing conditions for animals were approved by Institutional Animal Care and Use Committee of National Institute for Physiological Sciences, Fujita Health University and Ritsumeikan University.

Consent for publication

Not applicable.

Availability of data and materials

The datasets generated and/or analysed during the current study are available in the [Mouse Phenotype Database] repository, [http://www.mouse-phenotype.org/]

Competing interests

The authors declare that they have no competing interests.

Funding

This work was supported by Precursory Research for Embryonic Science and Technology (PRESTO) from the Japan Science and Technology Agency, by grants from the Ministry of Education program Grants-inAid for Scientific Research (B) (grant number 24390.019), by MEXT Supported Program for the Strategic Research Foundation at Private Universities, $2013-2017$ (grant number S1511027), by the Takeda Science Foundation, by Grant-in-Aid for Scientific Research on Innovative Areas (Comprehensive Brain Science 
Network) from the Ministry of Education, Science, Sports and Culture of Japan (221S0003) and R-GIRO (Ritsumeikan Global Innovation Research Organization).

Authors' contributions

TH contributed to data acquisition and analysis of brain extraction, HPLC-ECD and RT-qPCR and ELISA, and co-wrote the manuscript. SI and TY contributed to data acquisition of behavior test battery. SH, KT and TM supervised behavior test battery and performed part of them. KT and CK designed this projects and write this manuscript. All authors read and approved the final manuscript.

Acknowledgements

We appreciate Dr.Takahisa Furukawa to provide $\operatorname{Trpm}^{-/-}$mice. We appreciate Dr. Shigetada Nakanishi for provide the opportunities to use HPLC-ECD. We are indebted to Dr. Steven H. DeVries for helpful suggestions.

\section{References}

1. Koike C, Obara T, Uriu Y, Numata T, Sanuki R, Miyata K, et al. TRPM1 is a component of the retinal ON bipolar cell transduction channel in the mGluR6 cascade. Proc Natl Acad Sci U S A. 2010;107:332-7.

2. Koike C, Numata T, Ueda H, Mori Y, Furukawa T. TRPM1: A vertebrate TRP channel responsible for retinal ON bipolar function. Cell Calcium. 2010;48:95-101.

3. Nakamura M, Sanuki R, Yasuma TR, Onishi A, Nishiguchi KM, Koike C, et al. TRPM1 mutations are associated with the complete form of congenital stationary night blindness. Mol Vis. 2010;16:42537.

4. Kniffin CL. CHROMOSOME 15q13.3 DELETION SYNDROME. In: Online Mendelian Inheritance in Man [Internet]. Johns Hopkins Univ. [cited 2020 Nov 19]. Available from: https://www.omim.org/entry/612001.

5. 15q13.3 microdeletion syndrome. In: Genetic and Rare Diseases Information Center [Internet]. Natl. Inst. Heal. [cited 2020 Nov 19]. Available from: https://rarediseases. info.nih.gov/diseases/10296/15q13.3-microdeletion-syndrome.

6. Yin J, Chen W, Yang H, Xue M, Schaaf CP. Chrna7 deficient mice manifest no consistent neuropsychiatric and behavioral phenotypes. Sci Rep. 2017;7:1-10.

7. Yin J, Chen W, Chao ES, Soriano S, Wang L, Wang W, et al. Otud7a Knockout Mice Recapitulate Many Neurological Features of 15q13.3 Microdeletion Syndrome. Am J Hum Genet. 2018;102:296-308.

8. Xu Y, Dhingra A, Fina ME, Koike C, Furukawa T, Vardi N. mGluR6 deletion renders the TRPM1 channel in retina inactive. J Neurophysiol. 2012;107:948-57.

9. Masu M, Iwakabe H, Tagawa Y, Miyoshi T, Yamashita M, Fukuda Y, et al. Specific deficit of the ON response in visual transmission by targeted disruption of the mGluR6 gene. Cell. 1995;80:757-65. 
10. Takeuchi H, Horie S, Moritoh S, Matsushima H, Hori T, Kimori Y, et al. Different Activity Patterns in Retinal Ganglion Cells of TRPM1 and mGluR6 Knockout Mice. Biomed Res Int. 2018;2018:1-6.

11. Takao K, Miyakawa T. Investigating gene-to-behavior pathways in psychiatric disorders: The use of a comprehensive behavioral test battery on genetically engineered mice. Ann N Y Acad Sci. 2006;1086:144-59.

12. Yamashita N, Takahashi A, Takao K, Yamamoto T, Kolattukudy P, Miyakawa T, et al. Mice lacking collapsin response mediator protein 1 manifest hyperactivity, impaired learning and memory, and impaired prepulse inhibition. Front Behav Neurosci. 2013;7:1-10.

13. Takao K, Miyakawa T. Light/dark Transition Test for Mice. JoVE. 2006;1:1-3.

14. Shibasaki K, Sugio S, Takao K, Yamanaka A, Miyakawa T, Tominaga M, et al. TRPV4 activation at the physiological temperature is a critical determinant of neuronal excitability and behavior. Pflugers Arch Eur J Physiol. 2015;467:2495-507.

15. Fujioka R, Nii T, Iwaki A, Shibata A, Ito I, Kitaichi K, et al. Comprehensive behavioral study of mGluR3 knockout mice: Implication in schizophrenia related endophenotypes. Mol Brain. 2014;7:1-18.

16. Ageta-Ishihara N, Yamakado H, Morita T, Hattori S, Takao K, Miyakawa T, et al. Chronic overload of SEPT4, a parkin substrate that aggregates in Parkinson's disease, causes behavioral alterations but not neurodegeneration in mice. Mol Brain. 2013;6:1-14.

17. Koshimizu H, Takao K, Matozaki T, Ohnishi H, Miyakawa T. Comprehensive behavioral analysis of cluster of differentiation 47 knockout mice. PLoS One. 2014;9:1-12.

18. Tamada K, Tomonaga S, Hatanaka F, Nakai N, Takao K, Miyakawa T, et al. Decreased exploratory activity in a mouse model of $15 q$ duplication syndrome; implications for disturbance of serotonin signaling. PLoS One. 2010;5:1-11.

19. Iwakabe H, Katsuura G, Ishibashi C, Nakanishi S. Impairment of pupillary responses and optokinetic nystagmus in the mGluR6-deficient mouse. Neuropharmacology. 1997;36:135-43.

20. Kupers R, Ptito M. Compensatory plasticity and cross-modal reorganization following early visual deprivation. Neurosci Biobehav Rev. 2014;41:36-52.

21. Slimani H, Danti S, Ptito M, Kupers R. Pain perception is increased in congenital but not late onset blindness. PLoS One. 2014;9:1-6.

22. Li Y, Hu X, Yu Y, Zhao K, Saalmann YB, Wang L. Feedback from human posterior parietal cortex enables visuospatial category representations as early as primary visual cortex. Brain Behav. 2018;8:1-15.

23. Touj S, Tokunaga R, Al Aïn S, Bronchti G, Piché M. Pain Hypersensitivity is Associated with Increased Amygdala Volume and c-Fos Immunoreactivity in Anophthalmic Mice. Neuroscience. 2019;418:3749.

24. Rauschecker JP, Tian B, Korte M, Egert U. Crossmodal changes in the somatosensory vibrissa/barrel system of visually deprived animals. Proc Natl Acad Sci U S A. 1992;89:5063-7. 
25. Noppeney U. The effects of visual deprivation on functional and structural organization of the human brain. Neurosci Biobehav Rev. 2007;31:1169-80.

26. Cecchetti L, Ricciardi E, Handjaras G, Kupers R, Ptito M, Pietrini P. Congenital blindness affects diencephalic but not mesencephalic structures in the human brain. Brain Struct Funct. 2016;221:1465-80.

27. Chebat DR, Schneider FC, Ptito M. Neural Networks Mediating Perceptual Learning in Congenital Blindness. Sci Rep. 2020;10:1-10.

28. Ptito M, Schneider FCG, Paulson OB, Kupers R. Alterations of the visual pathways in congenital blindness. Exp Brain Res. 2008;187:41-9.

29. Petrus E, Isaiah A, Jones AP, Li D, Wang H, Lee HK, et al. Crossmodal Induction of Thalamocortical Potentiation Leads to Enhanced Information Processing in the Auditory Cortex. Neuron. 2014;81:664-73.

30. Larsen DLD, Luu JD, Burns ME, Krubitzer L. What are the effects of severe visual impairment on the cortical organization and connectivity of primary visual cortex? Front Neuroanat. 2009;3:1-16.

31. Hikishima K, Komaki Y, Seki F, Ohnishi Y, Okano HJ, Okano H. In vivo microscopic voxel-based morphometry with a brain template to characterize strainspecific structures in the mouse brain. Sci Rep. 2017;7:1-9.

32. Dalrymple RA, McKenna Maxwell L, Russell S, Duthie J. NICE guideline review: Attention deficit hyperactivity disorder: diagnosis and management (NG87). Arch Dis Child - Educ Pract. 2020;105:289-93.

33. de la Peña JB, dela Peña IJ, Custodio RJ, Botanas CJ, Kim HJ, Cheong JH. Exploring the Validity of Proposed Transgenic Animal Models of Attention-Deficit Hyperactivity Disorder (ADHD). Mol Neurobiol Molecular Neurobiology. 2018;55:3739-54.

34. Liu GX, Cai GQ, Cai YQ, Sheng ZJ, Jiang J, Mei Z, et al. Reduced anxiety and depression-like behaviors in mice lacking GABA transporter subtype 1. Neuropsychopharmacology. 2007;32:1531-9.

35. Smith GW, Aubry JM, Dellu F, Contarino A, Bilezikjian LM, Gold LH, et al. Corticotropin releasing factor receptor 1-deficient mice display decreased anxiety, impaired stress response, and aberrant neuroendocrine development. Neuron. 1998;20:1093-102.

36. Masurel-Paulet A, Andrieux J, Callier P, Cuisset JM, Le Caignec C, Holder M, et al. Delineation of 15q13.3 microdeletions. Clin Genet. 2010;78:149-61.

37. Pagnamenta AT, Wing K, Akha ES, Knight SJL, Bölte S, Schmötzer G, et al. A 15q13.3 microdeletion segregating with autism. Eur J Hum Genet. 2009;17:687-92.

38. Alsagob M, Salih MA, Hamad MHA, Al-Yafee Y, Al-Zahrani J, Al-Bakheet A, et al. First report of two successive deletions on chromosome 15q13 cytogenetic bands in a boy and girl: Additional data to 15q13.3 syndrome with a report of high IQ patient. Mol Cytogenet Molecular Cytogenetics. 2019;12:1-6.

39. Hoppman-Chaney N, Wain K, Seger PR, Superneau DW, Hodge JC. Identification of single gene deletions at 15q13.3: Further evidence that CHRNA7 causes the 15q13.3 microdeletion syndrome 
phenotype. Clin Genet. 2013;83:345-51.

40. Sharp AJ, Mefford HC, Li K, Baker C, Skinner C, Stevenson RE, et al. A recurrent 15q13.3 microdeletion syndrome associated with mental retardation and seizures. Nat Genet. 2008;40:322-8.

41. Miller DT, Shen Y, Weiss LA, Korn J, Anselm I, Bridgemohan C, et al. Microdeletion/duplication at 15q13. 2q13.3 among individuals with features of autism and other neuropsychiatric disorders. J Med Genet. 2009;46:242-8.

42. Van Bon BWM, Mefford HC, Menten B, Koolen DA, Sharp AJ, Nillesen WM, et al. Further delineation of the 15q13 microdeletion and duplication syndromes: A clinical spectrum varying from nonpathogenic to a severe outcome. J Med Genet. 2009;46:511-23.

43. Popovici C, Busa T, Missirian C, Milh M, Moncla A, Philip N. Mosaic 15q13.3 deletion including CHRNA7 gene in monozygotic twins. Eur J Med Genet Elsevier Masson SAS. 2013;56:274-7.

44. Park S, Kim B-N, Cho S-C, Kim J-W, Shin M-S, Yoo H-J, et al. Baseline Severity of Parent-Perceived Inattentiveness Is Predictive of the Difference Between Subjective and Objective Methylphenidate Responses in Children with Attention-Deficit/Hyperactivity Disorder. J Child Adolesc Psychopharmacol. 2013;23:410-4.

45. de Sonneville LMJ, Njiokiktjien C, Bos H. Methylphenidate and information processing. part 1: Differentiation between responders and nonresponders; part 2: Efficacy in responders. J Clin Exp Neuropsychol Routledge. 1994;16:877-97.

46. Li Y, Yin A, Sun X, Zhang M, Zhang J, Wang P, et al. Deficiency of tumor suppressor NDRG2 leads to attention deficit and hyperactive behavior. J Clin Invest. 2017;127:4270-84.

47. Ey E, Torquet N, de Chaumont F, Lévi-Strauss J, Ferhat AT, Le Sourd AM, et al. Shank2 Mutant Mice Display Hyperactivity Insensitive to Methylphenidate and Reduced Flexibility in Social Motivation, but Normal Social Recognition. Front Mol Neurosci Frontiers Media SA. 2018;11:365.

48. Wrenn CC, Heitzer AM, Roth AK, Nawrocki L, Valdovinos MG. Effects of clonidine and methylphenidate on motor activity in Fmr1 knockout mice. Neurosci Lett. 2015;585:109-13.

49. Forsingdal A, Fejgin K, Nielsen V, Werge T, Nielsen J. 15q13.3 Homozygous Knockout Mouse Model Display Epilepsy-, Autism-and Schizophrenia-Related Phenotypes. Transl Psychiatry. 2016;6:1-9.

50. Ueda Y, Tammitsu N, Imai H, Honda Y, Shichida Y. Recovery of rod-mediated a-wave during lightadaptation in mGluR6-deficient mice. Vision Res. 2006;46:1655-64.

51. Morgans CW, Zhang J, Jeffrey BG, Nelson SM, Burke NS, Duvoisin RM, et al. TRPM1 is required for the depolarizing light response in retinal ON-bipolar cells. Proc Natl Acad Sci U S A. 2009;106:19174-8.

52. Klinge C, Eippert F, Röder B, Büchel C. Corticocortical connections mediate primary visual cortex responses to auditory stimulation in the blind. J Neurosci. 2010;30:12798-805.

53. Leinweber M, Ward DR, Sobczak JM, Attinger A, Keller GB. A Sensorimotor Circuit in Mouse Cortex for Visual Flow Predictions. Neuron. 2017;95:1420-32. 
54. Pakan JM, Francioni V, Rochefort NL. Action and learning shape the activity of neuronal circuits in the visual cortex. Curr Opin Neurobiol. 2018;52:88-97.

55. Hishida R, Horie M, Tsukano H, Tohmi M, Yoshitake K, Meguro R, et al. Feedback inhibition derived from the posterior parietal cortex regulates the neural properties of the mouse visual cortex. Eur $\mathrm{J}$ Neurosci. 2019;50:2970-87.

56. Wittenberg GF, Werhahn KJ, Wassermann EM, Herscovitch P, Cohen LG. Functional connectivity between somatosensory and visual cortex in early blind humans. Eur J Neurosci. 2004;20:1923-7.

57. Oancea E, Vriens J, Brauchi S, Jun J, Splawski I, Clapham DE. TRPM1 forms ion channels associated with melanin content in melanocytes. Sci Signal. 2009;2:1-11.

58. Li Z, Sergouniotis PI, Michaelides M, Mackay DS, Wright GA, Devery S, et al. Recessive Mutations of the Gene TRPM1 Abrogate ON Bipolar Cell Function and Cause Complete Congenital Stationary Night Blindness in Humans. Am J Hum Genet. 2009;85:711-9.

59. Klooster J, Blokker J, ten Brink JB, Unmehopa U, Fluiter K, Bergen AAB, et al. Ultrastructural localization and expression of TRPM1 in the human retina. Investig Ophthalmol Vis Sci. 2011;52:8356-62.

60. Gebhardt C, von B und Halbach, Hadler O, Harteneck MD, Albrecht C D. A novel form of capsaicinmodified amygdala LTD mediated by TRPM1. Neurobiol Learn Mem. Elsevier Inc.; 2016;136:1-12.

\section{Tables}

Due to technical limitations, table 1 is only available as a download in the Supplemental Files section.

\section{Figures}

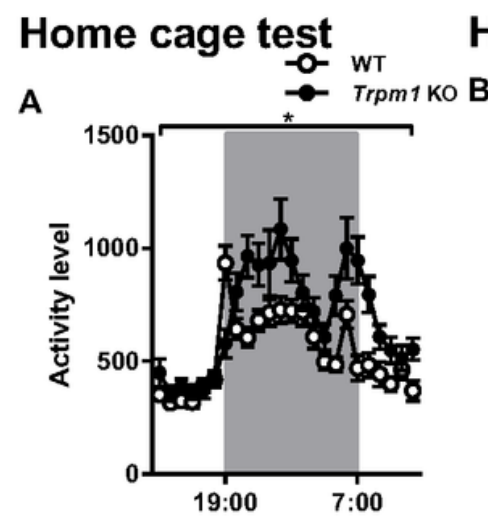

Hot plate test

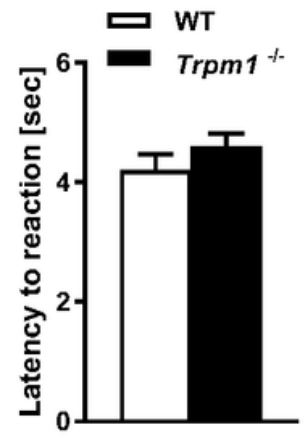

Acourstic startle response and prepulse inhibition
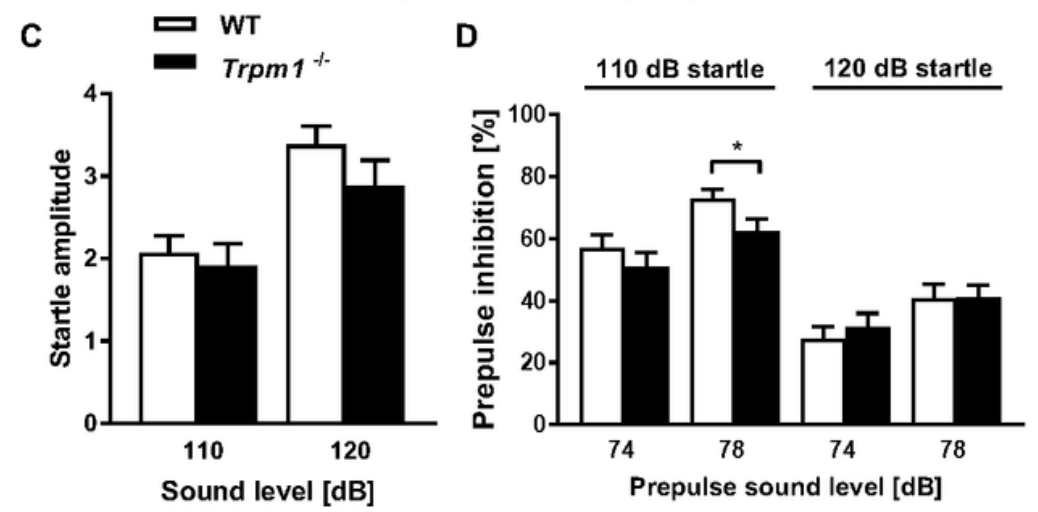

Figure 1

Physical characteristics of Trpm1-/- mice (A) Daily activity averaging 6 days in the home cage; $n=22$ for both genotypes. (B) latency to the first response in the hot plate test. $n=24$ for both genotypes. (C, D) 
Acoustic startle response/prepulse inhibition tests; (C) the amplitude of the startle response to the 110 and $120 \mathrm{~dB}$ acoustic stimuli, (D) the percentage of prepulse inhibition at the 74 and $78 \mathrm{~dB}$ prepulse sound level. $n=24$ for both genotypes. ${ }^{*} P<0.05$; repeated measures two-way ANOVA (A), Student t test (B-D).
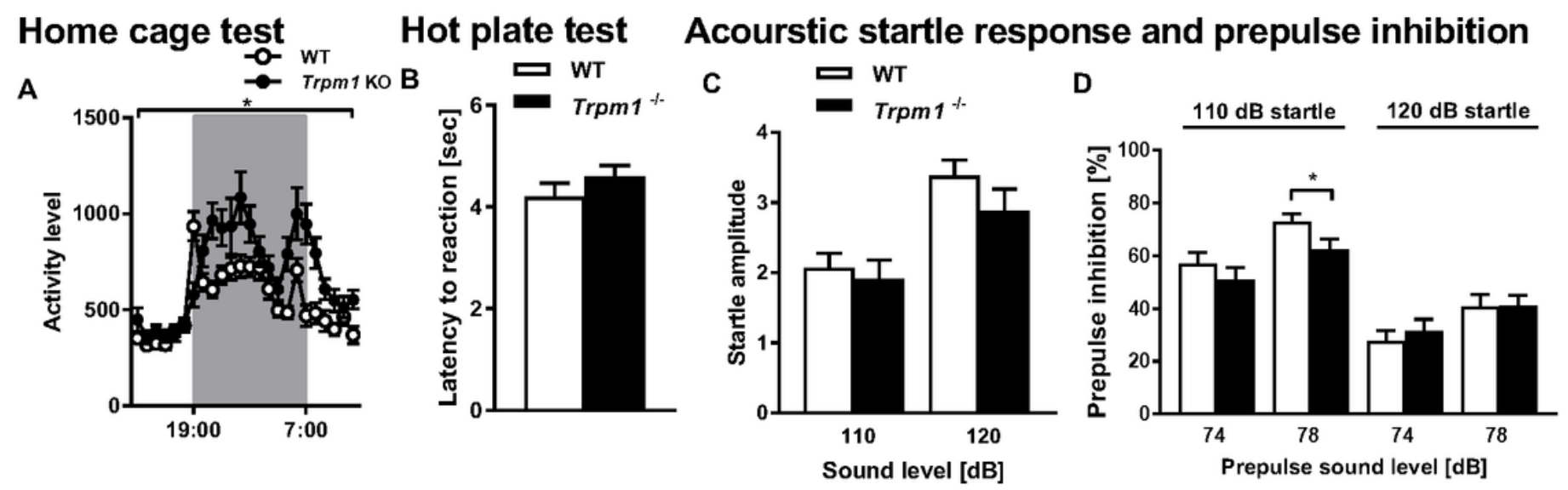

\section{Figure 1}

Physical characteristics of Trpm1-/- mice (A) Daily activity averaging 6 days in the home cage; $n=22$ for both genotypes. (B) latency to the first response in the hot plate test. $n=24$ for both genotypes. (C, D) Acoustic startle response/prepulse inhibition tests; (C) the amplitude of the startle response to the 110 and $120 \mathrm{~dB}$ acoustic stimuli, (D) the percentage of prepulse inhibition at the 74 and $78 \mathrm{~dB}$ prepulse sound level. $n=24$ for both genotypes. ${ }^{*} P<0.05$; repeated measures two-way ANOVA (A), Student t test (B-D). 
Light/Dark transition test

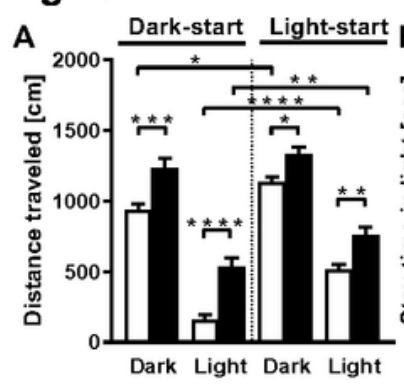

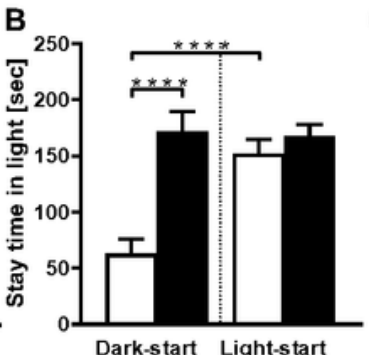

Dark-start Light-start
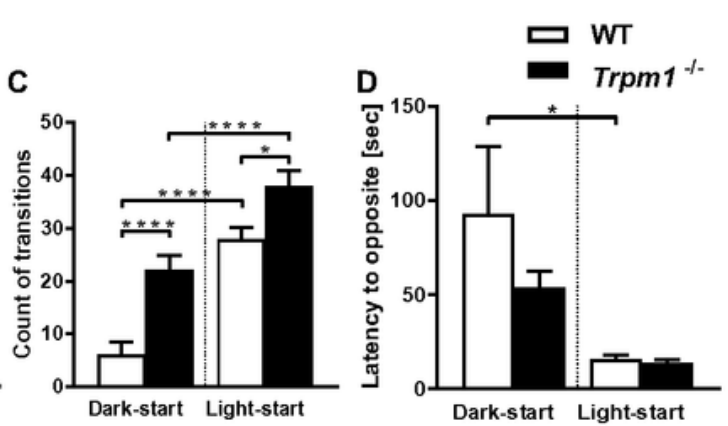

Open field test

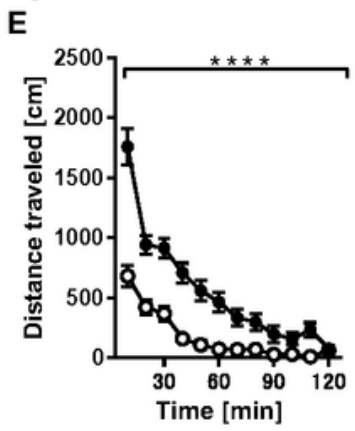

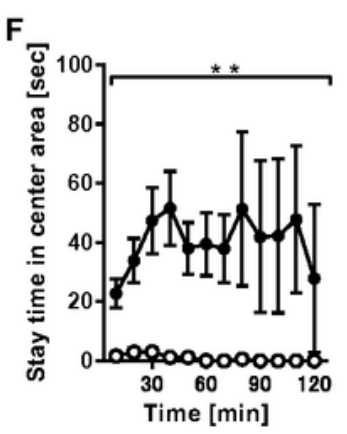

G

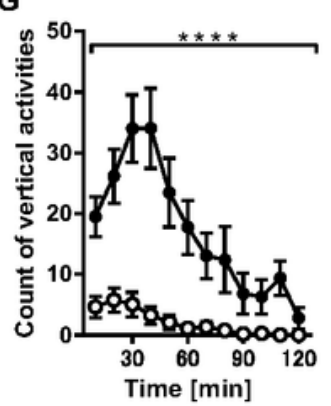

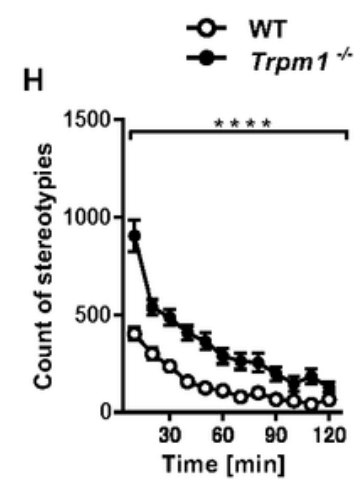

I

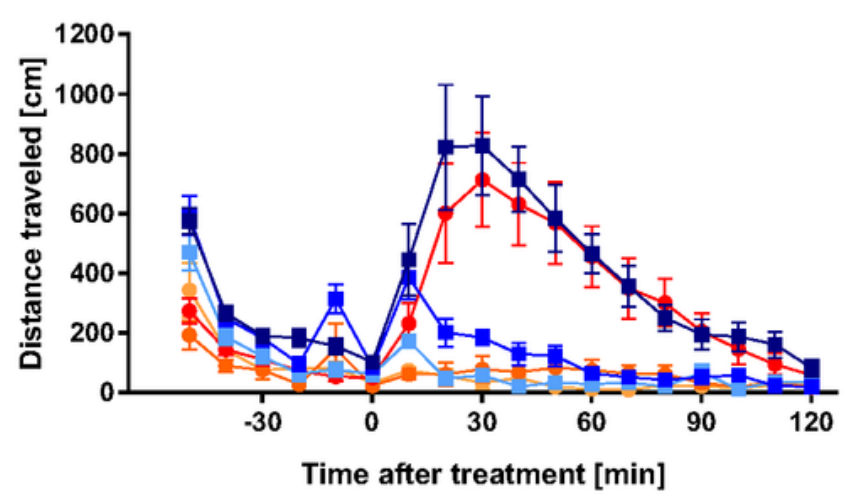

\section{Elevated plus maze test}

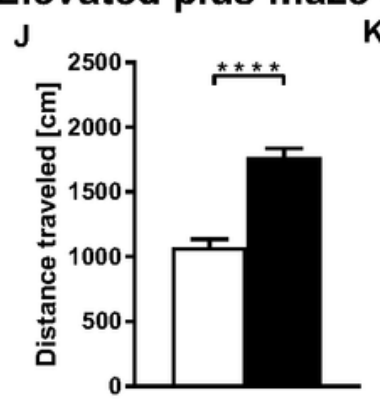

$\mathrm{K}$

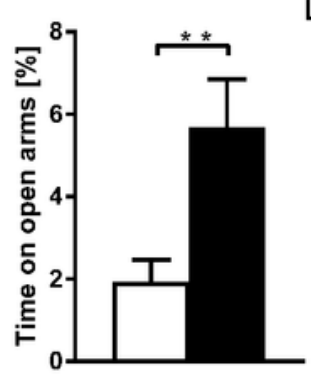

L

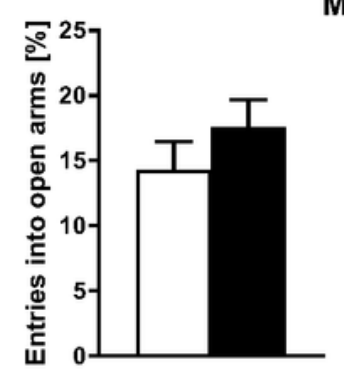

$\left.\begin{array}{l}-W T+\text { Saline } \\ -W T+3 \mathrm{mg} / \mathrm{kg} \text { MPH } \\ -6 \mathrm{WT}+10 \mathrm{mg} / \mathrm{kg} \mathrm{MPH} \quad] *\end{array}\right]$ *

$-\operatorname{Trpm}^{*}+$ Saline

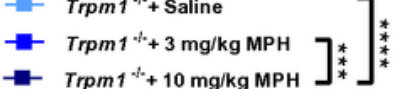


mg/mL MPH, $\mathrm{n}=12$ for WT + $10 \mathrm{mg} / \mathrm{mL}$ MPH, $\mathrm{n}=11$ for Trpm1-/- + saline, $\mathrm{n}=12$ for Trpm1-/ - + 3 mg/mL MPH, $\mathrm{n}=12$ for Trpm1-/- + 10 mg/mL MPH. (J-M) Elevated plus maze test; (J) the total distance traveled, $(K)$ time spent on open arms, (L) number of entries into open arms, (M) and number of entries. $\mathrm{n}=24$ for both genotypes. ${ }^{*} \mathrm{P}<0.05$, ${ }^{\star *} \mathrm{P}<0.01$, ${ }^{\star *} \mathrm{P}<0.001$, ${ }^{\star *} * * \mathrm{P}<0.0001$; two-way ANOVA followed by Tukey's multi comparison test (A-D), repeated measures two-way ANOVA (E-H), repeated measures two-way ANOVA followed by Tukey's multi comparison test (I), Student's t test (J, L, M), Welch's t test $(\mathrm{K})$

\section{Light/Dark transition test}

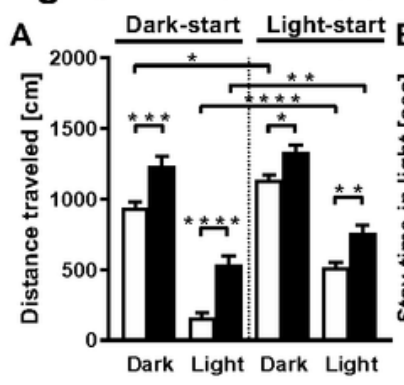

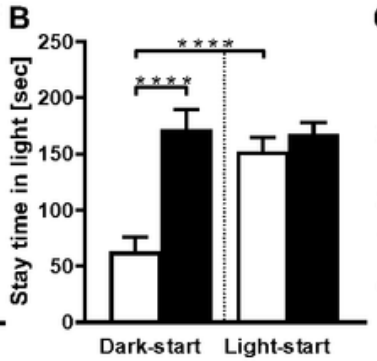
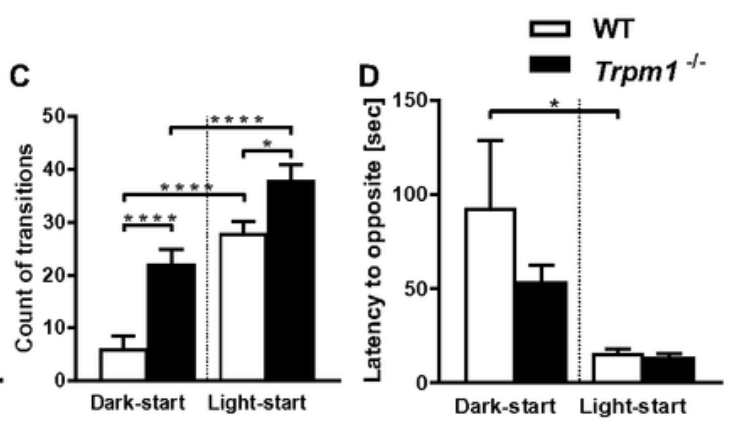

Open field test

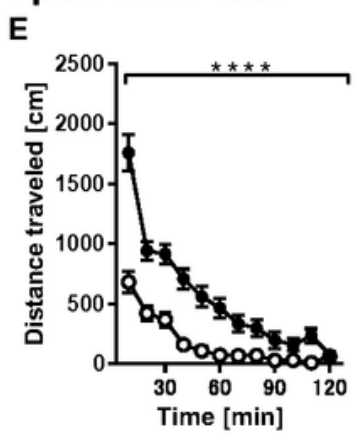

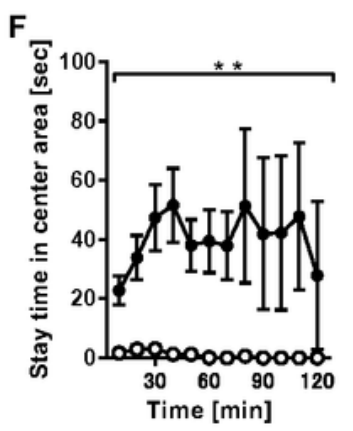
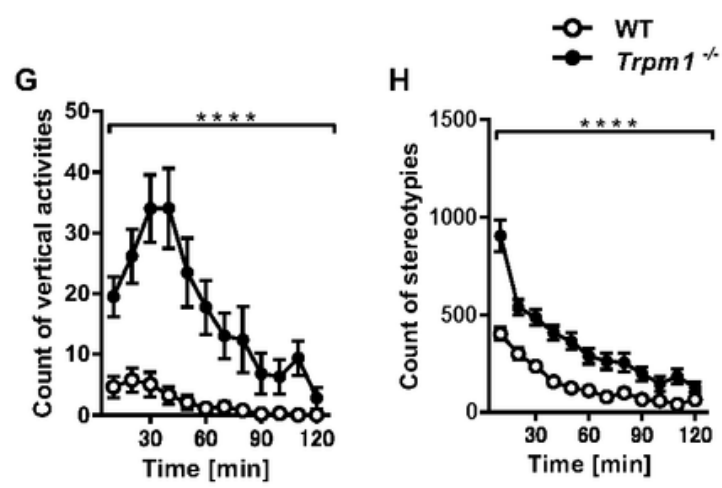

$$
\text { I }
$$

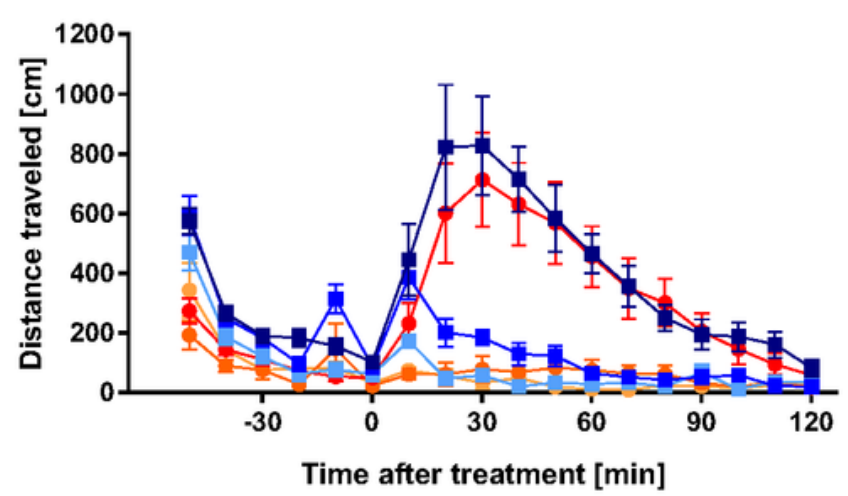

\section{Elevated plus maze test}

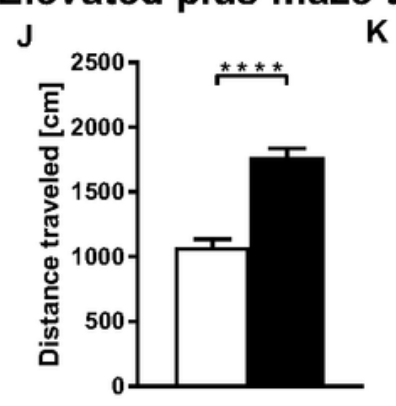

$\mathrm{K}$

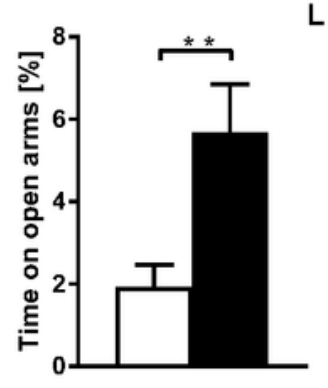

L

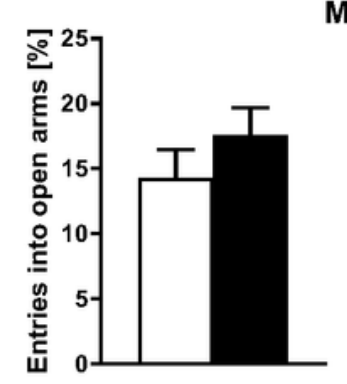

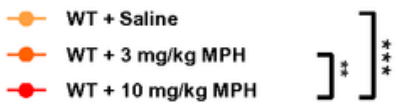

$\left.\left.\left.\begin{array}{l}-\operatorname{Trpm} 1^{*}+\text { Saline } \\ -\left[\operatorname{Trpm} 1^{*}+3 \mathrm{mg} / \mathrm{kg} \mathrm{MPH}\right. \\ -\operatorname{Trpm} 1^{*}+10 \mathrm{mg} / \mathrm{kg} \mathrm{MPH}\end{array}\right]\right]_{*}^{*}\right]_{*}^{*}$ 


\section{Figure 2}

Locomotor activity and anxiety-like behavior of Trpm1-/- mice (A-D) Light/Dark transition test; (A) the total distance traveled, (B) time spent in light, (C) the number of transitions, (D) the latency of opposite side. $n=24$ for both genotypes. $(E-H)$ Open field test; $(E)$ the total distance traveled, $(F)$ time spent in center of the field, $(G)$ The number of vertical activities, $(H)$ The number of stereotypies. $n=24$ for both genotypes. (I) The total distance traveled with treatment of MPH. $n=9$ for WT + Saline, $n=9$ for WT +3 $\mathrm{mg} / \mathrm{mL}$ MPH, $\mathrm{n}=12$ for WT $+10 \mathrm{mg} / \mathrm{mL}$ MPH, $\mathrm{n}=11$ for Trpm1-/- + saline, $\mathrm{n}=12$ for Trpm $1-/-+3$ $\mathrm{mg} / \mathrm{mL} \mathrm{MPH}, \mathrm{n}=12$ for Trpm1-/- + $10 \mathrm{mg} / \mathrm{mL}$ MPH. (J-M) Elevated plus maze test; $(\mathrm{J})$ the total distance traveled, $(K)$ time spent on open arms, $(\mathrm{L})$ number of entries into open arms, $(\mathrm{M})$ and number of entries. $\mathrm{n}=24$ for both genotypes. ${ }^{*} \mathrm{P}<0.05$, ${ }^{\star *} \mathrm{P}<0.01$, ${ }^{\star \star \star} \mathrm{P}<0.001$, ${ }^{\star \star * *} \mathrm{P}<0.0001$; two-way ANOVA followed by Tukey's multi comparison test (A-D), repeated measures two-way ANOVA (E-H), repeated measures two-way ANOVA followed by Tukey's multi comparison test (I), Student's $t$ test $(J, L, M)$, Welch's $\mathrm{t}$ test $(\mathrm{K})$ 
A

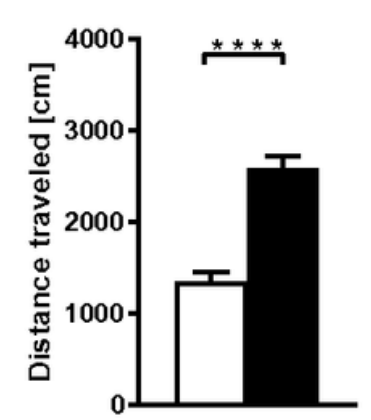

B

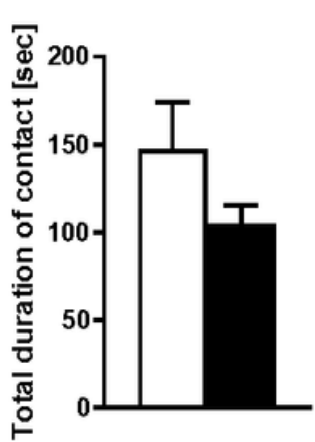

C

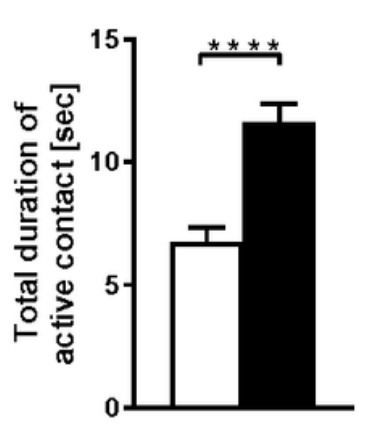

口 WT

E

Trpm1 $^{\text {-1 }}$
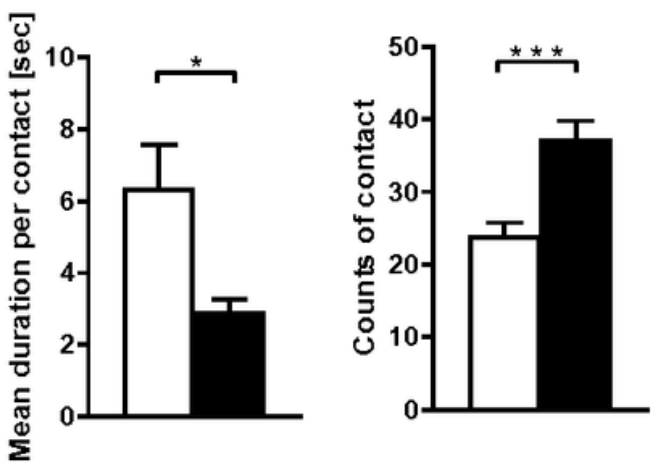

Social interaction test (social preference)

$\mathbf{F}$

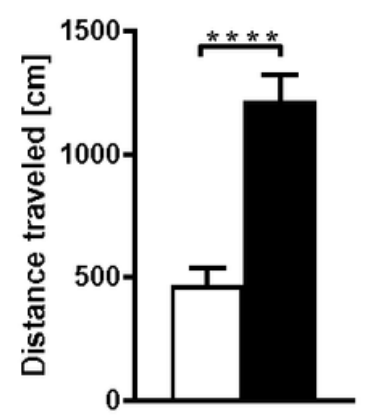

G

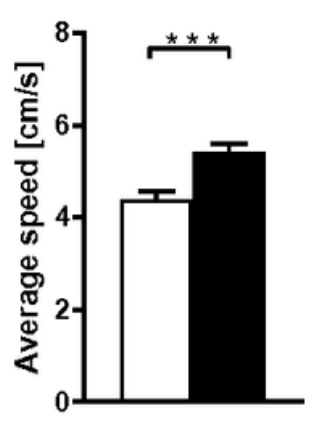

$\mathrm{H}$

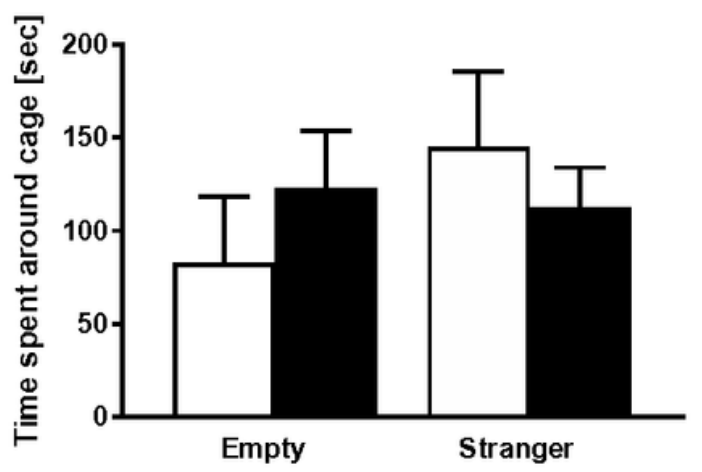

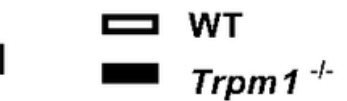

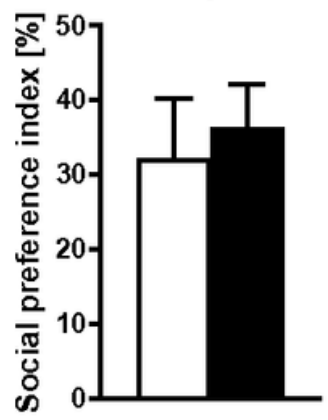

\section{Social interaction test (Novel preference)}

J

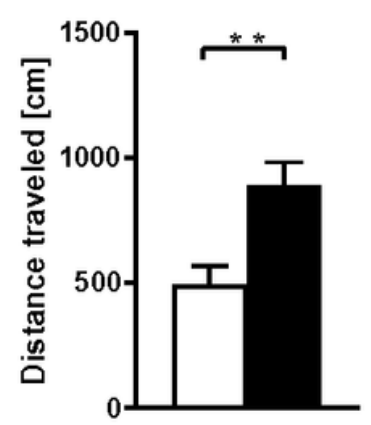

K

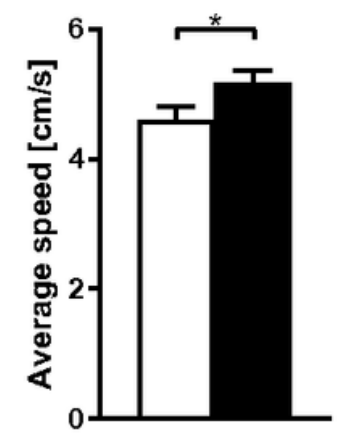

L

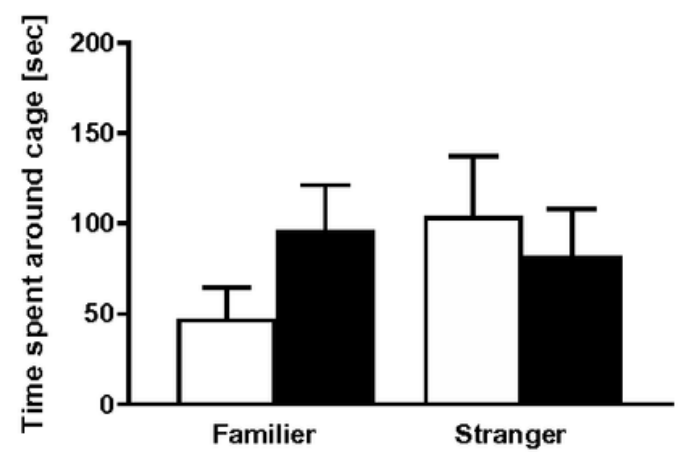

M

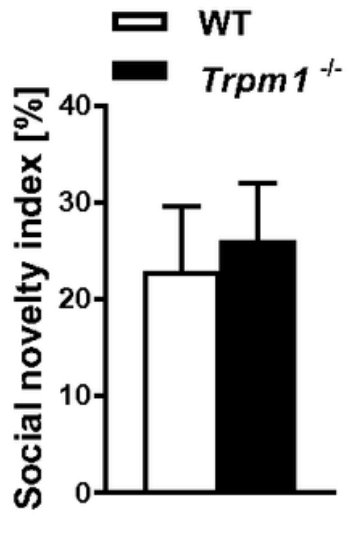

Figure 3

Social interaction of Trpm1-/- mice (A-E) Social interaction in novel environment; (A) the total distance traveled, (B) total duration of contact, (C) total duration of active contact, (D) the number of contacts, (E) mean duration per contact. $n=12$ for both genotypes. $(F-I)$ Social preference; $(F)$ the total distance traveled, $(\mathrm{G})$ average speed, $(\mathrm{H})$ time spent in each chamber, $(\mathrm{I})$ social preference (calculated as the ratio of time spent in stranger chamber to all chamber). $n=24$ for both genotypes. (J-M) Social novel preference; $(J)$ the total distance traveled, $(K)$ average speed, $(L)$ time spent in each chamber, $(M)$ novel preference (calculated as the ratio of time spent in stranger chamber to all chambers; $n=24$ for both 


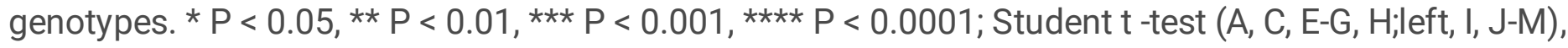
Welch $t$-test (B,D, H;right).

\section{Social interaction test (novel environment)}

A

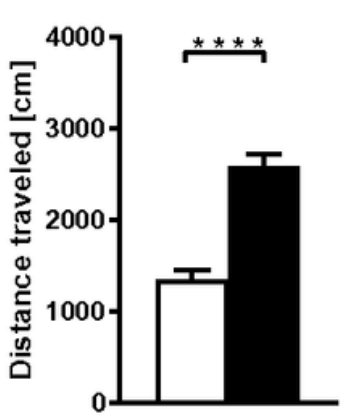

B

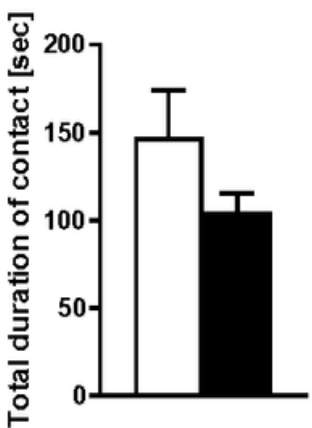

C

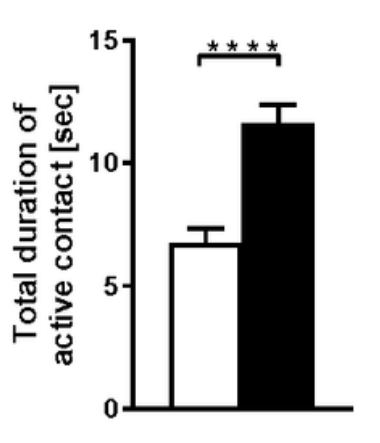

口 WT

E

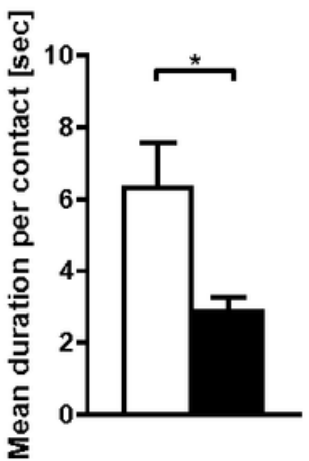

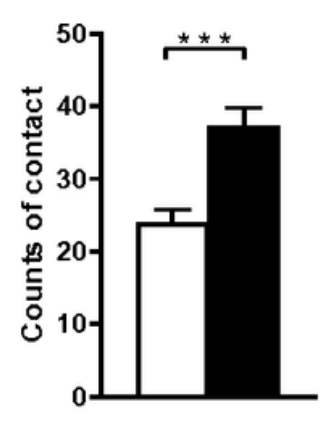

Social interaction test (social preference)

$\mathbf{F}$

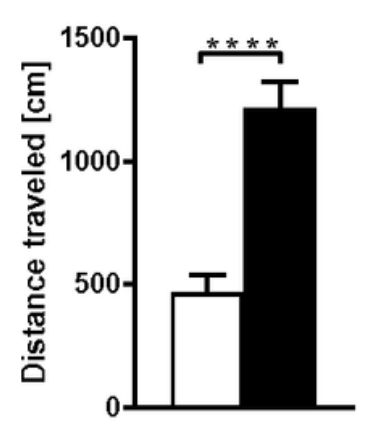

G

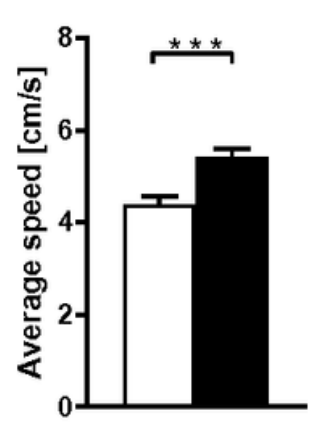

$\mathrm{H}$

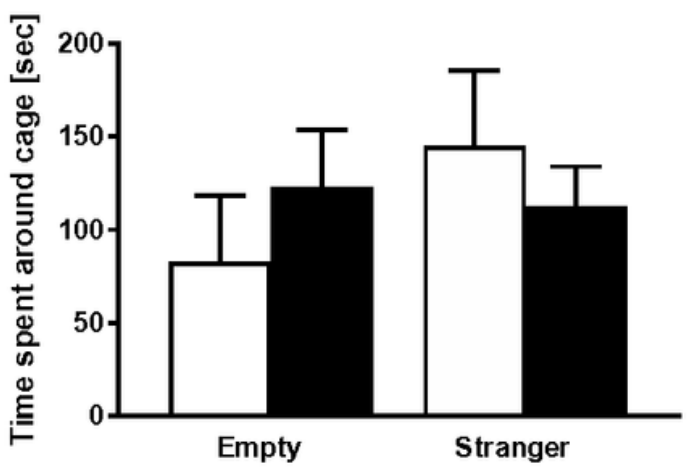

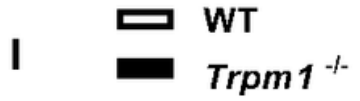

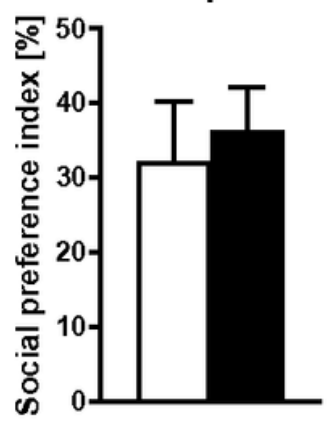

Social interaction test (Novel preference)

J

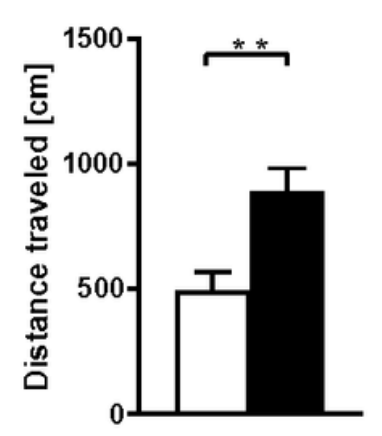

K

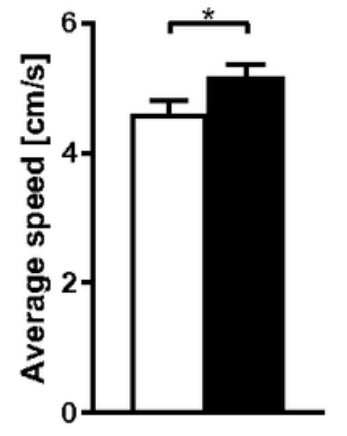

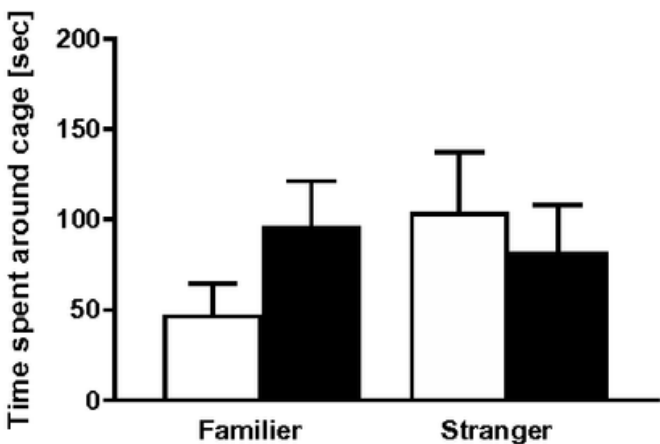

Figure 3

Social interaction of Trpm1-/- mice (A-E) Social interaction in novel environment; (A) the total distance traveled, (B) total duration of contact, (C) total duration of active contact, (D) the number of contacts, (E) mean duration per contact. $n=12$ for both genotypes. $(F-I)$ Social preference; $(F)$ the total distance traveled, $(\mathrm{G})$ average speed, $(\mathrm{H})$ time spent in each chamber, $(\mathrm{I})$ social preference (calculated as the ratio of time spent in stranger chamber to all chamber). $\mathrm{n}=24$ for both genotypes. (J-M) Social novel 
preference; $(J)$ the total distance traveled, $(K)$ average speed, $(L)$ time spent in each chamber, $(M)$ novel preference (calculated as the ratio of time spent in stranger chamber to all chambers; $n=24$ for both

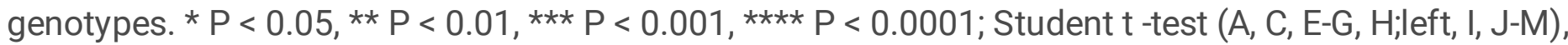
Welch t -test (B,D, H;right).

\section{Fear conditioning test}
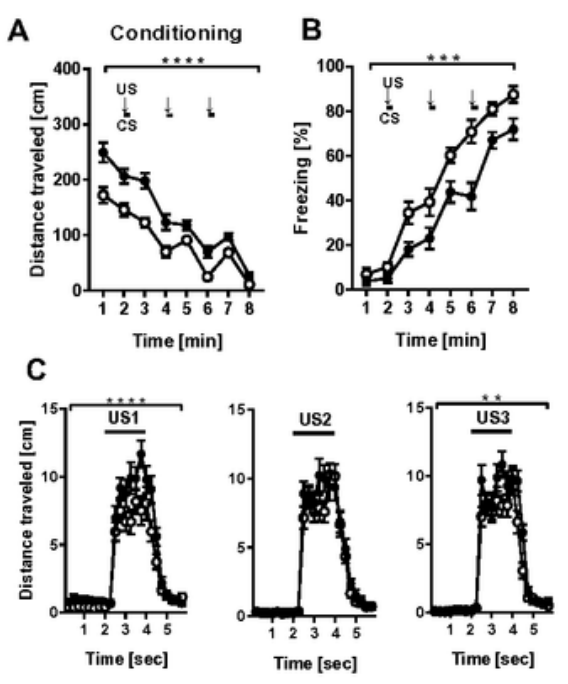

D

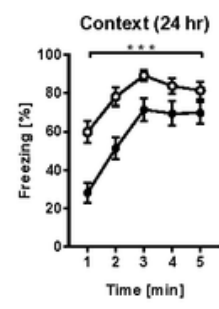

E

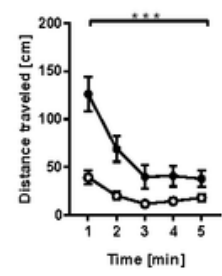

- wT

$\rightarrow \operatorname{Trpm} 1 \%$
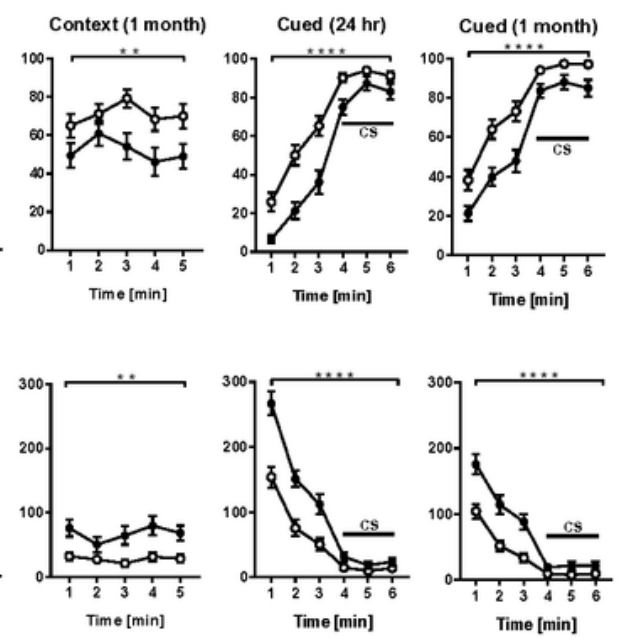

\section{Barnes maze test}

$\mathbf{F}$
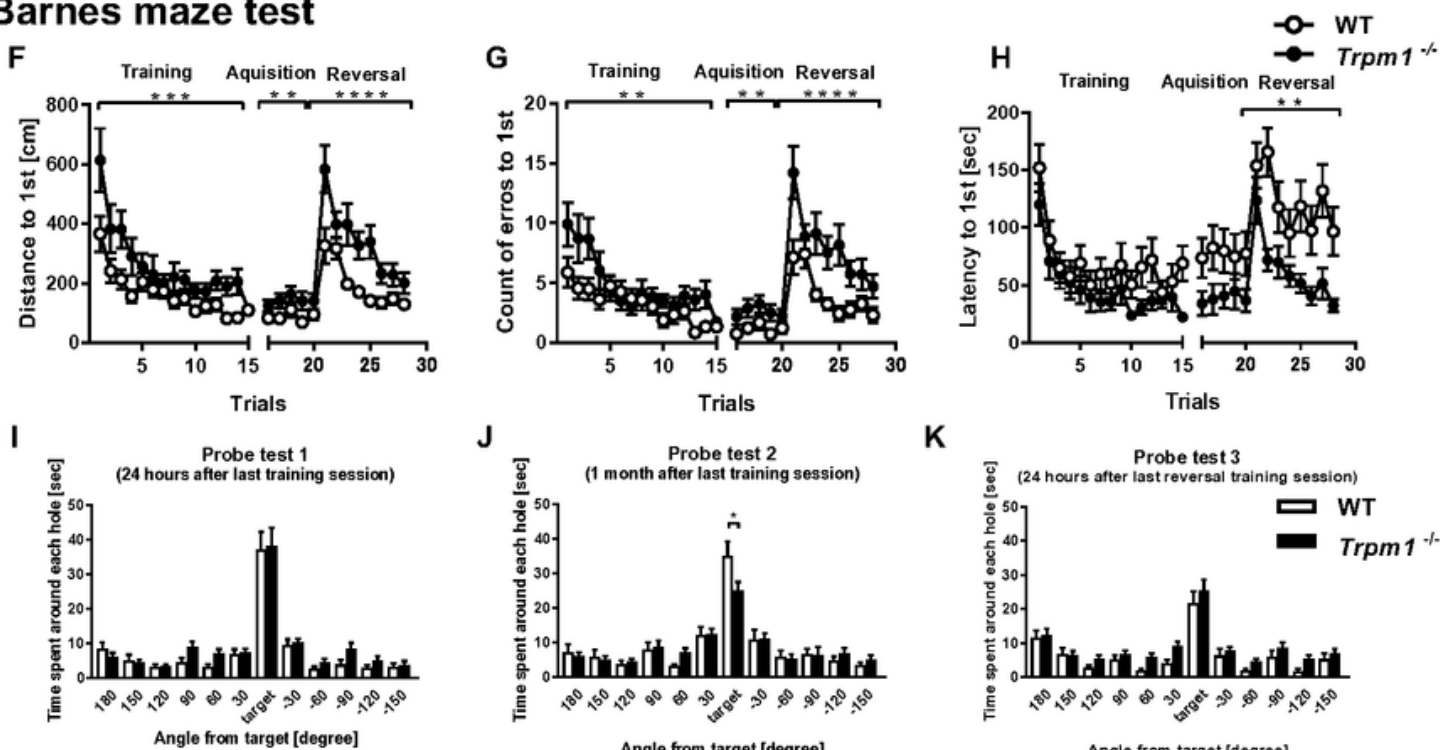

K

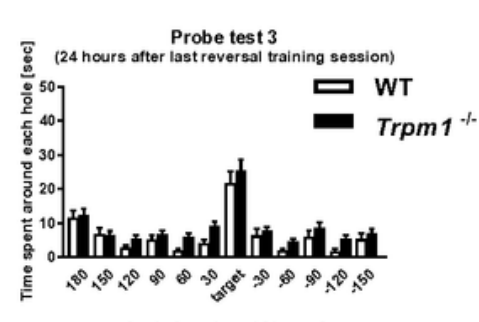

\section{T-maze spontaneous alteration test}

L

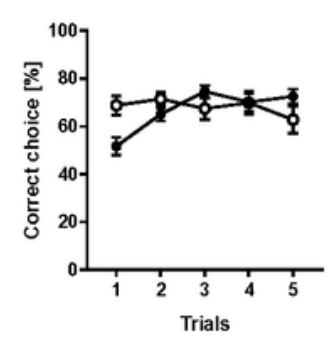

M

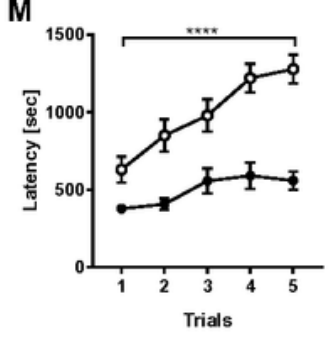

-0 WT

N

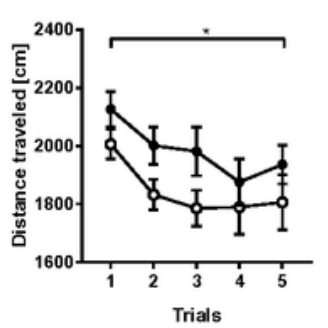

Figure 4 
Cognitive function of Trpm1-/- mice (A-E) Fear conditioning test; (A) distance traveled in the conditioning phase, $(\mathrm{B})$ the percentage of the freezing time in the conditioning phase. Conditioned stimulus (CS: white noise) and unconditioned stimulus (US: foot shock) were presented, (C) distance traveled during and after foot shocks, (D) the percentage of the freezing time in the context tests or cued tests one day and 30 days after conditioning, (E) distance traveled in the context tests or cued tests one day and 30 days after conditioning. $n=24$ for both genotypes. ( $F-K)$ Barnes maze test; $(F)$ the distance, $(G)$ the count of the error, $(H)$ the latency to first reach the correct hole above the escape box in the training, acquisition and reversal sessions, (I-K) Time spent around each hole in the probe trial conducted 24 hours (I), 1 month $(\mathrm{J})$ after the last training session and 24 hours after last reversal training session (K). $n=24$ for both genotypes. (L-N) T-maze forced alternation task test; (L) the percentage of correct response, $(M)$ the latency, $(N)$ distance traveled. $n=24$ for both genotypes. ${ }^{*} P<0.05,{ }^{*} \mathrm{P}<0.01$, ${ }^{\star \star *} \mathrm{P}<$ 0.001 , $* \star \star \star P<~ 0.0001$; repeated measures two-way ANOVA $(\mathrm{A}-\mathrm{H}, \mathrm{L}-\mathrm{N})$, Student $\mathrm{t}$-test $(\mathrm{l}, \mathrm{K})$, Welch $\mathrm{t}$-test $(\mathrm{J})$. 
Fear conditioning test
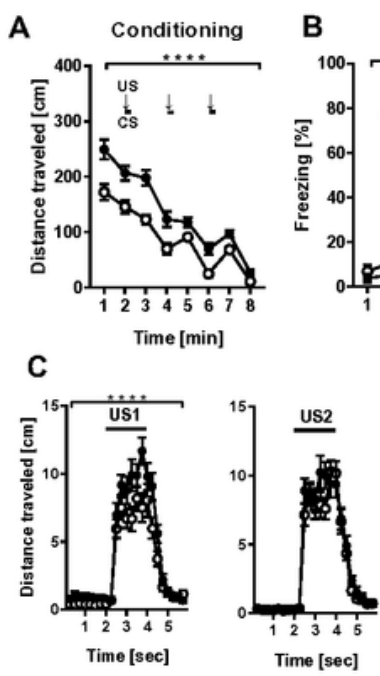

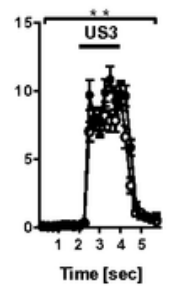

D

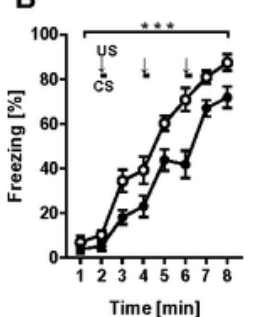

Time $[\mathrm{sec}]$

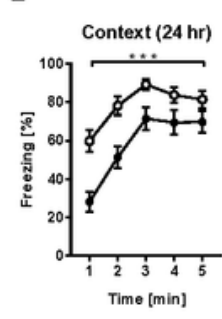

E

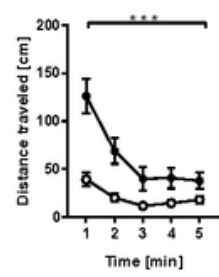

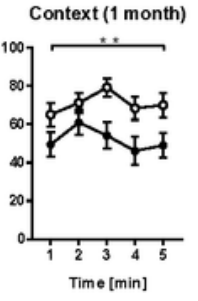

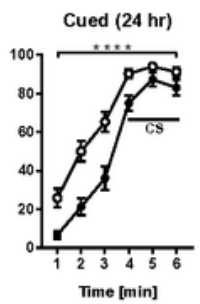

- - wT

$\rightarrow \operatorname{Trpm} 1 \%$
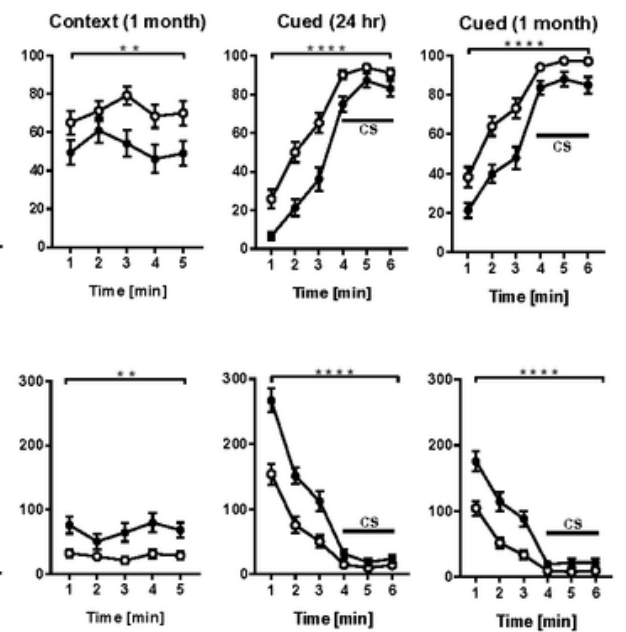

\section{Barnes maze test}
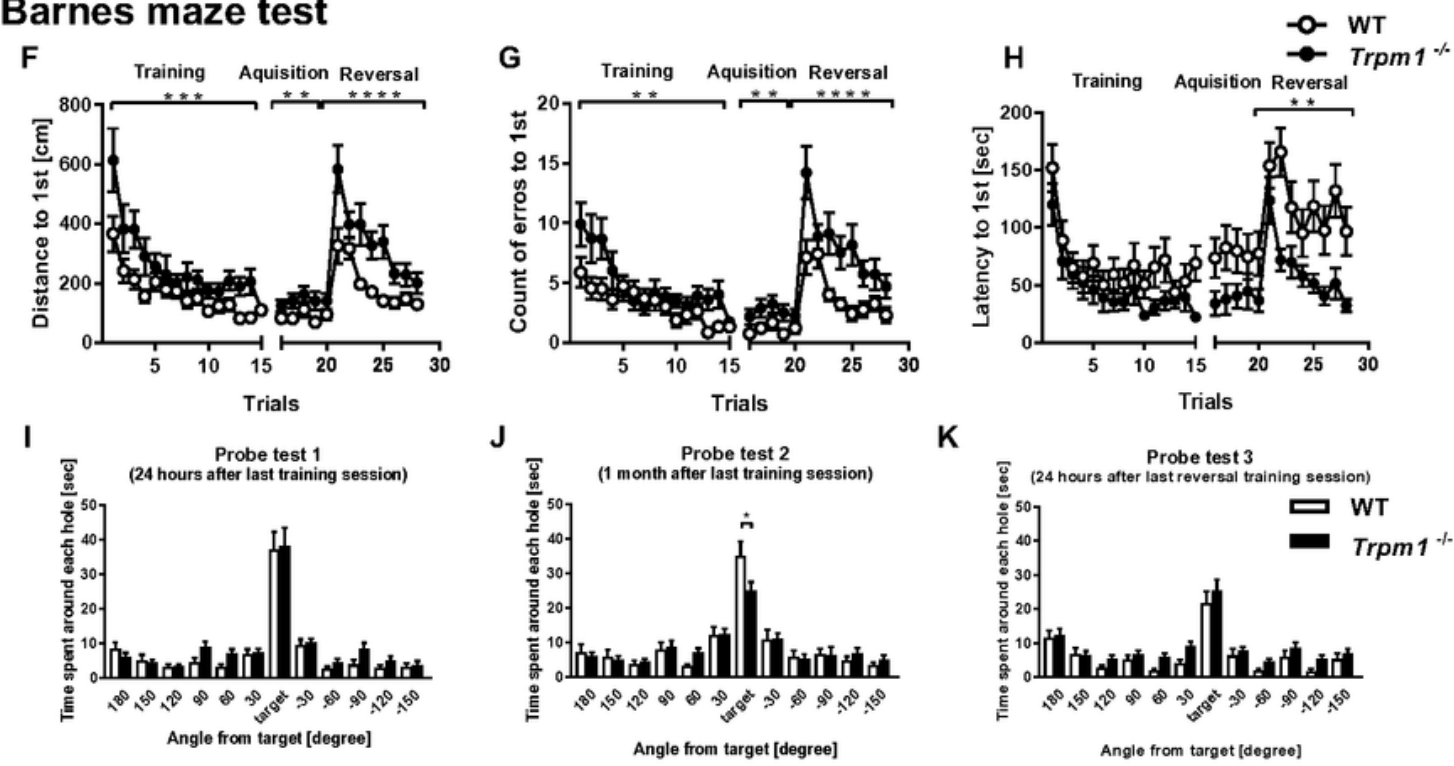

K

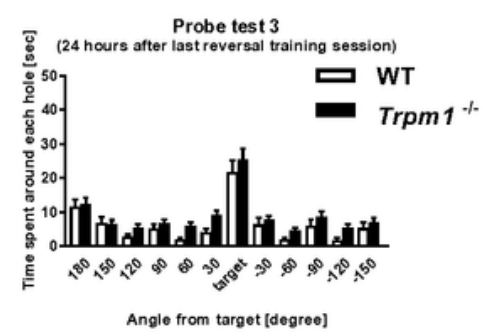

\section{T-maze spontaneous alteration test}

L

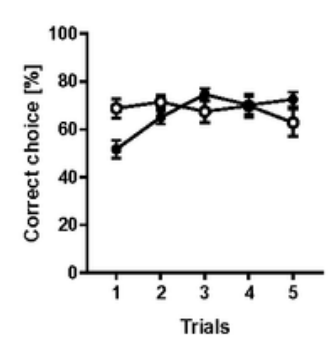

M

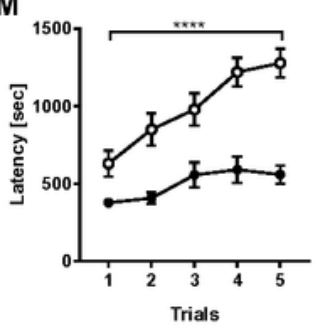

$\multimap$ WT
$-\quad \operatorname{Trpm1} \%$

N

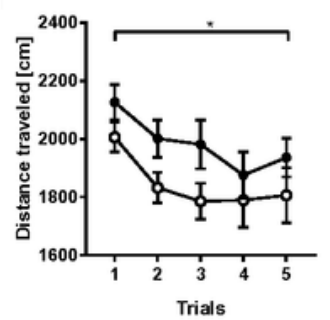

Figure 4

Cognitive function of Trpm1-/- mice (A-E) Fear conditioning test; (A) distance traveled in the conditioning phase, $(B)$ the percentage of the freezing time in the conditioning phase. Conditioned stimulus (CS: white noise) and unconditioned stimulus (US: foot shock) were presented, (C) distance traveled during and after foot shocks, (D) the percentage of the freezing time in the context tests or cued tests one day and 30 days after conditioning, (E) distance traveled in the context tests or cued tests one 
day and 30 days after conditioning. $n=24$ for both genotypes. ( $F-K)$ Barnes maze test; $(F)$ the distance, $(\mathrm{G})$ the count of the error, $(\mathrm{H})$ the latency to first reach the correct hole above the escape box in the training, acquisition and reversal sessions, (I-K) Time spent around each hole in the probe trial conducted 24 hours (I), 1 month $(\mathrm{J})$ after the last training session and 24 hours after last reversal training session (K). $n=24$ for both genotypes. (L-N) T-maze forced alternation task test; ( $L$ ) the percentage of correct response, $(M)$ the latency, $(N)$ distance traveled. $n=24$ for both genotypes. ${ }^{*} P<0.05,{ }^{\star \star} P<0.01,{ }^{\star \star *} P<$ $0.001, * \star * \star \mathrm{P}<0.0001$; repeated measures two-way ANOVA $(\mathrm{A}-\mathrm{H}, \mathrm{L}-\mathrm{N})$, Student $\mathrm{t}$-test $(\mathrm{I}, \mathrm{K})$, Welch $\mathrm{t}$-test $(\mathrm{J})$.
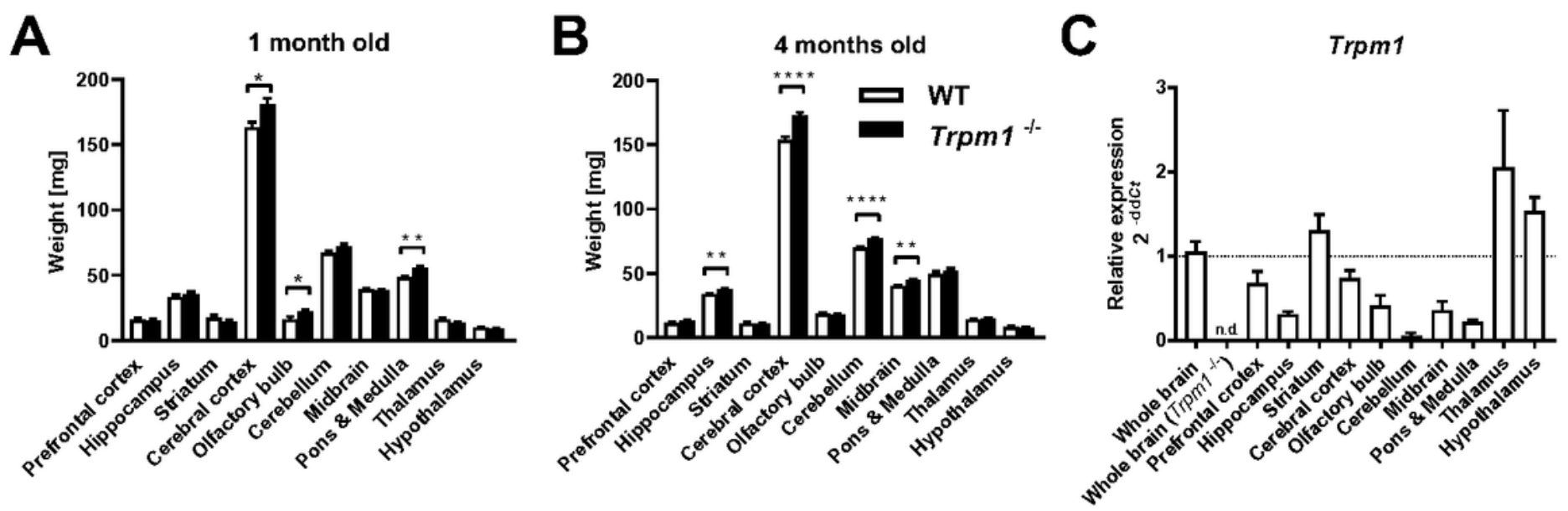

\section{Cerebellum}
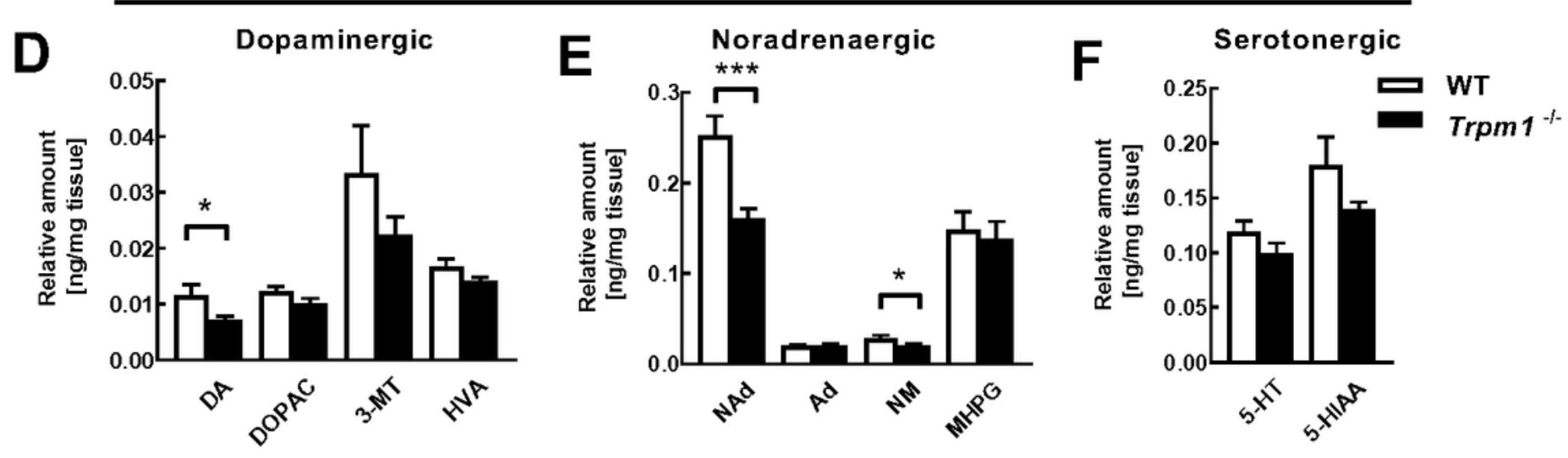

Figure 5

Abnormal Structural and biochemical change of Trpm1 -/- mice (A, B) The Brain weight at 1 month old (A), $n=5$ WT, 4 Trpm1 -/- and 4 months old (B), $n=24$ for both genotypes. (C) The expression of Trpm1 gene in WT brain. $\mathrm{n}=4$ for both genotypes. All amplification data were normalized with mean cycle threshold (Ct) value of WT whole brain group for $\Delta \mathrm{Ct}$ and normalized with $\beta$-actin for $\Delta \Delta \mathrm{Ct}$. Trpm1 mRNA was not detectable in whole brain of Trpm1-/- mice. (D-F) Quantification of monoamine neurotransmitters in cerebellum at 4 months old; (D) dopaminergic, (E) noradrenergic, $(F)$ serotonergic neurotransmitter and their metabolites. DOPAC: 3,4-dihydroxyphenylacetic acid, 3-MT: 3methoxytyramine, HVA: homovanillic acid, Ad: adrenaline, NM: normetanephrine, MHPG: 3-methoxy-4hydroxyphenylglycol, 5-HIAA: 5-hydroxyindoleacetic acid. $n=24$ for both genotypes. ${ }^{*} P<0.05,{ }^{*} P<0.01$,

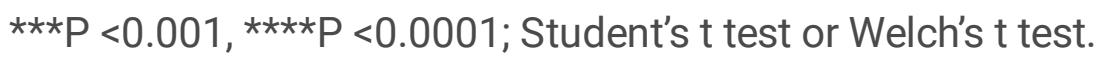



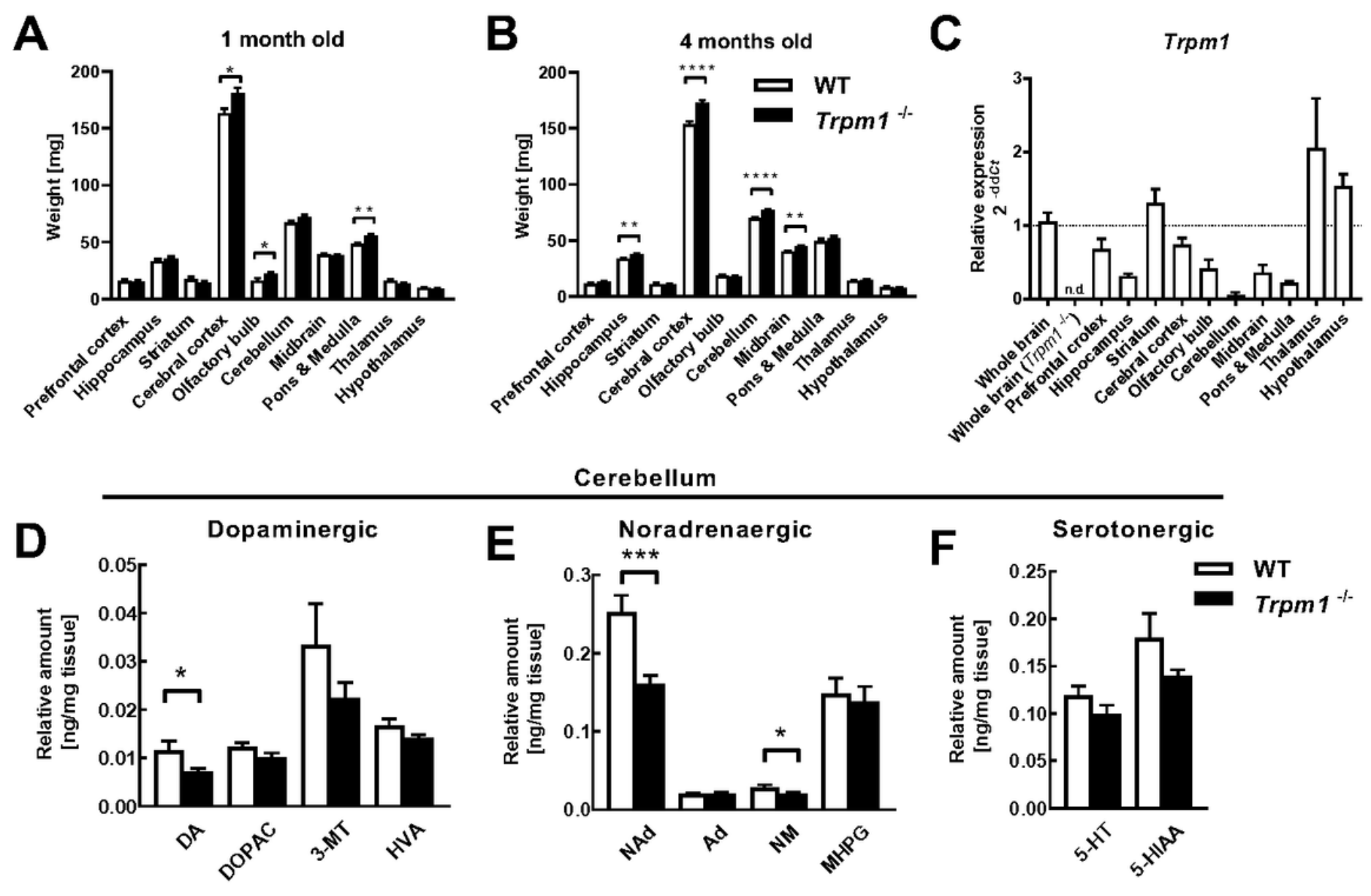

Figure 5

Abnormal Structural and biochemical change of Trpm1 -/- mice (A, B) The Brain weight at 1 month old (A), $n=5$ WT, 4 Trpm $1-/-$ and 4 months old (B), $n=24$ for both genotypes. (C) The expression of Trpm1 gene in WT brain. $\mathrm{n}=4$ for both genotypes. All amplification data were normalized with mean cycle threshold (Ct) value of WT whole brain group for $\Delta \mathrm{Ct}$ and normalized with $\beta$-actin for $\Delta \Delta \mathrm{Ct}$. Trpm1 mRNA was not detectable in whole brain of Trpm1-/- mice. (D-F) Quantification of monoamine neurotransmitters in cerebellum at 4 months old; (D) dopaminergic, $(E)$ noradrenergic, $(F)$ serotonergic neurotransmitter and their metabolites. DOPAC: 3,4-dihydroxyphenylacetic acid, 3-MT: 3-

methoxytyramine, HVA: homovanillic acid, Ad: adrenaline, NM: normetanephrine, MHPG: 3-methoxy-4hydroxyphenylglycol, 5-HIAA: 5-hydroxyindoleacetic acid. $n=24$ for both genotypes. ${ }^{*} P<0.05,{ }^{*} \mathrm{P}<0.01$, ${ }^{\star} * * \mathrm{P}<0.001, * \star \star \star \mathrm{P}<0.0001$; Student's $\mathrm{t}$ test or Welch's $\mathrm{t}$ test.

\section{Supplementary Files}

This is a list of supplementary files associated with this preprint. Click to download.

- HorietalTable1.pdf

- HorietalTable1.pdf 
- HorietalFigS1.pdf

- HorietalFigS1.pdf

- HorietalFigS2.pdf

- HorietalFigS2.pdf

- HorietalTableS1.pdf

- HorietalTables1.pdf 